\title{
Compulsory face mask policies do not affect community mobility in Germany
}

\author{
Roxanne Kovacs* $\quad$ Maurice Dunaiski ${ }^{\dagger} \quad$ Janne Tukiainen ${ }^{\ddagger}$
}

June 12,2020

\begin{abstract}
There is currently a heated debate about whether the general public should be required to wear protective face masks to contain COVID-19. A key concern is that compulsory face mask policies will make the public feel safer, and may (due to risk compensation) undermine the most important public-health advice to contain COVID-19 - which is to reduce mobility and maintain social distancing. This study provides first evidence on the impact of compulsory face mask policies on community mobility. We use a difference-in-differences design, which exploits the staggered implementation of compulsory face mask policies by German states. We use anonymised GPS data from Google's Location History feature to measure daily mobility in public spaces. We find no evidence suggesting that compulsory face mask policies affect community mobility in public spaces in Germany. We can rule out even small increases in mobility that are larger than 0.03 standard deviations.
\end{abstract}

Keywords: COVID-19, face masks, social distancing, community mobility JEL Codes: D9, H12, I12, I18

${ }^{*}$ London School of Hygiene \& Tropical Medicine, Department of Global Health and Development, Keppel St, Bloomsbury, London WC1E 7HT, United Kingdom. email: roxanne.kovacs@lshtm.ac.uk

${ }^{\dagger}$ London School of Economics \& Political Science, Department of Government, Houghton St, Holborn, London WC2A 2AE, United Kingdom. email: m.r.dunaiski@lse.ac.uk

${ }_{\ddagger}^{\ddagger}$ Department of Economics, Turku School of Economics, Rehtorinpellonkatu 3, FI-20014 University of Turku; VATT Institute for Economic Research, Arkadiankatu 7, Helsinki FI-00101. email: janne.tukiainen@utu.fi 


\section{Introduction}

The ongoing coronavirus disease (COVID-19) pandemic has, as of June 2020, led to the death of over 380,000 people [WHO, 2020] and is expected to trigger a severe economic crisis, with global GDP growth predicted to fall to $-3 \%$ [IMF, 2020]. One of the main ways in which governments have attempted to contain the spread of COVID-19 is through non-pharmaceutical interventions targeting citizens' behaviour. Policies that aim to curtail the spread of COVID-19 centre around reducing citizens' mobility and social contacts in order to disrupt the chain of transmission. Examples include closing schools, banning public gatherings, social distancing rules or lock-downs forbidding individuals to leave their homes [Mellan et al., 2020].

There is currently a heated debate about whether the general public should be required to wear protective face masks to further reduce the spread of COVID-19. For instance, the US Centres for Disease Control [CDC, 2020a] advocate for the use of face masks by the general public, whilst the World Health Organization does not [WHO, 2020]. ${ }^{1}$ Nonetheless, over 50 countries already require the wearing of face masks in public spaces [Al Jazeera News, 2020]. Those arguing against introducing compulsory face mask policies frequently point to limited evidence on effectiveness, concerns about individuals wearing masks incorrectly, as well as high demand on masks reducing availability for healthcare workers [Feng et al., 2020, Greenhalgh et al., 2020]. Another key argument against making face masks compulsory, which motivates this paper, is the concern that individuals will feel safer and might therefore disregard the most important public-health advice to contain the spread of COVID-19 which is to reduce mobility and maintain social distancing [Greenhalgh et al., 2020].

The effect of compulsory face mask policies on citizen's mobility is a priori ambiguous. In line

\footnotetext{
${ }^{1}$ As of June $5^{\text {th }}$ the WHO recommends that medical face masks should be worn by health workers, people with symptoms or those caring for them. In terms of non-medical (fabric masks) "the WHO does not recommend their widespread use among the public for control of COVID-19" [WHO, 2020], but recommends their use exclusively in spaces where social distancing cannot be maintained.
} 
with concerns of policymakers [The Guardian, 2020a,b], face masks could increase mobility due to risk compensation. A large economics literature examines behavioural responses to changes in perceived or actual risk [Peltzman, 1976]. Whilst the findings are mixed overall [Godlonton et al., 2016], a number of studies find evidence for risk-compensating behaviour, for instance, more risky sexual behaviour among recipient of the HPV vaccine [Kapoor, 2008], car accidents as a result of seat belt laws [Miller and Blomquist, 1989] and bicycle helmets triggering dangerous driving by cars [Walker, 2007]. Risk compensating behaviour is therefore a plausible mechanism through which protective technologies such as face masks, that reduce personal risk (whether actual or perceived), could lead to an increase in mobility.

In contrast, salience and what we refer to as the "hassle factor" provide reasons to expect that compulsory face mask policies reduce mobility. Face masks differ from previously studied risk-reducing technologies as they need to be worn constantly (unlike one-off treatments such as vaccines). Face masks might therefore serve as a constant reminder to citizens that the COVID-19 pandemic is ongoing and serious. It is therefore possible that compulsory face masks increase the salience of the COVID-19 pandemic in individuals' decision making about their mobility [Van Der Pligt and De Vries, 1998]. Availability bias (where individuals judge events that come to mind more easily to be more likely) potentially exacerbates such an effect. For instance, studies have found that frequent exposure to drug advertisement influences individuals' perceptions about disease prevalence [An, 2008]. Face masks might similarly inflate perceptions about the true prevalence of COVID-19 - which could affect mobility decisions about whether to visit any public space (i.e. not only locations where face masks are required by law). Another way in which face masks differ from previously studied risk-reducing technologies is that that they are bothersome to use (much more so than, for instance, seat belts). Wearing a face mask creates disutility, as wearers suggest that masks can be hot, uncomfortable, humid, itchy and odorous [Li et al., 2005]. This disutility, which we refer to as the "hassle factor", can spoil the fun of non-essential outings and could incentivise individuals to minimise the frequency of essential outings - which could 
reduce mobility. Due to the extensively studied process of adaptation, through which one quickly adjusts to new or changed circumstances, we expect that any such effects should be short-lived [Dolan and Kahneman, 2008]. In addition, as the hassle factor only comes into play when masks are worn, it should primarily affect mobility in locations where face masks are required by law. ${ }^{2}$

This study provides first evidence on the effect of compulsory face mask policies on community mobility. To isolate the causal effect of such policies, we use a difference-in-differences design, which exploits the staggered introduction of policies requiring the wearing of face masks in shops and public transport by German states (Bundesländer). Saxony was the first state to introduce compulsory face masks on the $20^{\text {th }}$ of April 2020, Schleswig-Holstein was the last to do so on the $29^{\text {th }}$ of April 2020. To measure community mobility, we rely on the Google COVID-19 Community Mobility Reports, which use GPS data from Google's Location History to provide anonymised and aggregated (state-level) measures of the number of hours spent at home as well as the number of times public spaces are visited each day. Community mobility has been previously measured in this way in epidemiological studies [Mellan et al., 2020] to estimate the basic reproduction number $R_{0}$, which is a key parameter of transmission intensity and therefore highly relevant for containing the spread of COVID-19.

We measure community mobility within each German state between March $23^{\text {rd }}$ and May $21^{\text {st }}$ 2020. Our main outcome is an aggregate measure of mobility in public spaces, which captures visits to grocery and pharmacy shops, workplaces and transport hubs. We focus on an aggregate measure of mobility in public spaces, as we expect policymakers to be more interested in changes in overall mobility patterns. Nonetheless, we also report changes in mobility for specific public locations as well as in places of residence.

We do not find evidence to suggest that compulsory face mask policies affect community

\footnotetext{
${ }^{2}$ In a setting where face masks are voluntary, an additional reason why masks could reduce mobility is that individuals perceive masks as a signal for a larger preferred social distance by the wearer, as found by Seres et al. [2020]
} 
mobility in public spaces in Germany. Effect sizes are precisely estimated and we can rule out even small increases in mobility that are larger than 0.03 SD. We only find a small reduction in average community mobility on the day of the policy change (-0.14 SD), but find no longer-term effects thereafter. We also find no evidence suggesting that, beyond a shortterm increase during the first four days, compulsory face mask policies affect the number of hours spent at home, which is another "catch-all" measure of community mobility. We take this to suggest that these policies are complementary to interventions aimed at reducing mobility and disrupting the chain of transmission of COVID-19. When we examine mobility in specific locations, we find that mobility patterns are lower in grocery shops and pharmacies for five days following the introduction of compulsory face masks, but that the magnitude of the reduction is modest. We find no effects on mobility patterns in workplaces or transport hubs (subways, buses or train stations).

This paper makes three main contributions. First, it provides new evidence that is crucial to ongoing policy debates on how to best manage the COVID-19 pandemic. Policymakers and researchers have expressed concerns that making face masks compulsory could lead people to disregard measures that are key for containing COVID-19. For example, the UK government's Scientific Advisory Group for Emergencies (Sage) underlined that that there was a risk that compulsory face mask policies "could make people feel invincible and therefore be less likely to adhere to other rules around socialising and staying at home" [The Guardian, 2020b]. We are unable to provide evidence on important individual-level behaviours such as hand-washing or social distancing. However, community mobility plays a key role in reducing the spread of COVID-19 [Mellan et al., 2020] and we find no evidence to suggest that, in Germany, compulsory face mask policies led to an increase in mobility. If anything, we observe a temporary decrease in mobility in grocery shops and pharmacies. This is important information for policy-makers considering the costs and benefits of compulsory face mask policies, as such analyses likely do not have to account for spillovers on mobility. 
Second, we contribute to the small but rapidly growing literature using aggregate GPS data to study the effect of policies trying to contain the spread of COVID-19 on mobility patterns [Allcott et al., 2020, Wellenius et al., 2020, Dasgupta et al., 2020]. Using GPS data is one of the main alternatives to using surveys [Briscese et al., 2020, Jørgensen et al., 2020], which likely do not provide reliable data on mobility due to social desirability bias [Daoust et al., 2020].

Finally, our findings speak to the behavioural economics literature on risk compensation [Godlonton et al., 2016, Peltzman, 1976, Kapoor, 2008, Miller and Blomquist, 1989, Walker, 2007]. To our knowledge, only one previous study has examined the effect of face masks on risk compensating behaviour, finding that physical distancing increases by on average $9 \mathrm{~cm}$ when individuals wear masks - supposedly because others interpret face masks as a signal for a larger preferred distance [Seres et al., 2020]. Our paper complements the study by Seres et al. [2020] by providing first evidence from a large sample. Our study is also the first to investigate the general equilibrium effect of introducing compulsory face masks - where signalling is unlikely to play a role. We show that, even though compulsory face mask policies may reduce personal risk and risk imposed on others, there is no evidence of an undesirable aggregate effect on community mobility.

\section{Background}

Germany is frequently put forward as a positive example for how to manage the COVID-19 pandemic [The Guardian, 2020c]. As of June $5^{\text {th }} 2020$, there have been 183,271 confirmed cases of COVID-19 in Germany and 8,613 deaths [RKI, 2020]. There are arguably two main reasons for Germany's relative success in handling the COVID-19 pandemic. First, Germany started testing early and tested a broad sample of the population. This stands in contrast to some other European countries, which initially focused on testing elderly populations or 
those in critical care [Stafford, 2020]. Due to its federal healthcare system, Germany also does not face testing constraints created by having only a few central laboratories, as is the case in many other countries [Stafford, 2020]. Second, containment measures to reduce the population's mobility (e.g. closing schools, retail businesses and banning public gatherings), and thereby break the chain of transmission, began comparatively earlier than in other countries [Stafford, 2020].

Germany's 16 states introduced compulsory face mask policies at different times in late April 2020 (see Table 1). Saxony was the first state, on the April $20^{\text {th }} 2020$, followed by SaxonyAnhalt on April $23^{\text {th }}$ and Thuringia on April $24^{\text {th }}$. Twelve states adopted compulsory face mask policies on April 27 $7^{\text {th }}$, and Schleswig-Holstein followed suit on April $29^{\text {th }}$. In all states, the face mask requirement is fulfilled by wearing a non-surgical mask, bandana or scarf that covers mouth and nose (called Mund-Nasen-Bedeckung). Children under the age of six and people with disabilities are usually excluded from the face mask requirement. All states except Berlin made face masks compulsory in public transport and in shops at the same time. In Berlin, face masks first became compulsory in public transport (April $27^{\text {th }}$ ) and in shops two days later. As of June $5^{\text {th }}$, compulsory face mask policies remain in place in all German states, although some state governments have expressed a desire to abolish the requirement [Guardian, 2020, Die ZEIT, 2020].

In Appendix A we provide an overview of when other policies related to COVID-19 (e.g. school, retail and restaurant re-openings as well as lock-downs being relaxed) were implemented, given that these policies may have also affected community mobility in the study period. In some instances, these additional policy changes coincided with the introduction of compulsory face mask policies. Most of the overlap relates to secondary school re-openings, which coincide with the introduction of compulsory face masks in eleven of the sixteen states. Retail re-openings were implemented on the same day as compulsory face mask policies in only three states, compared to one state for lock-down relaxation and none for restaurant 
re-openings.

Even though compulsory face mask policies make it illegal not to wear a mask in designated spaces, only nine out of 16 states introduced fines for not wearing masks. ${ }^{3}$ Overall, the German approach "seems to be characterised more by appealing on compliance to rules rather than on enforcing them by micromanagement law" [Stafford, 2020].

Table 1: Implementation of compulsory face mask policies by German states in April 2020

\begin{tabular}{|c|c|c|}
\hline & Face masks not compulsory & Face masks compulsory \\
\hline April $19^{\text {th }}$ & $\begin{array}{l}\text { SN, ST, TH, BW, BY, BE, BB, HB, } \\
\text { HH, HE, MV, NI, NW, RP, SL, SH }\end{array}$ & \\
\hline April $20^{\text {th }}$ & $\begin{array}{l}\text { ST, TH, BW, BY, BE, BB, HB, HH, } \\
\text { HE, MV, NI, NW, RP, SL, SH }\end{array}$ & SN \\
\hline April $21^{\text {st }}$ & $\begin{array}{l}\text { ST, TH, BW, BY, BE, BB, HB, HH, } \\
\text { HE, MV, NI, NW, RP, SL, SH }\end{array}$ & SN \\
\hline April $22^{\text {nd }}$ & $\begin{array}{l}\text { ST, TH, BW, BY, BE, BB, HB, HH, } \\
\text { HE, MV, NI, NW, RP, SL, SH }\end{array}$ & SN \\
\hline April $23^{\text {rd }}$ & $\begin{array}{l}\text { TH, BW, BY, BE, BB, HB, HH, HE, } \\
\text { MV, NI, NW, RP, SL, SH }\end{array}$ & $\mathrm{SN}, \mathrm{ST}$ \\
\hline April $24^{\text {th }}$ & $\begin{array}{l}\text { BW, BY, BE, BB, HB, HH, HE, } \\
\text { MV, NI, NW, RP, SL, SH }\end{array}$ & $\mathrm{SN}, \mathrm{ST}, \mathrm{TH}$ \\
\hline April $25^{\text {th }}$ & $\begin{array}{l}\text { BW, BY, BE, BB, HB, HH, HE, } \\
\text { MV, NI, NW, RP, SL, SH }\end{array}$ & $\mathrm{SN}, \mathrm{ST}, \mathrm{TH}$ \\
\hline April $26^{\text {th }}$ & $\begin{array}{l}\text { BW, BY, BE, BB, HB, HH, HE, } \\
\text { MV, NI, NW, RP, SL, SH }\end{array}$ & $\mathrm{SN}, \mathrm{ST}, \mathrm{TH}$ \\
\hline April $27^{\text {th }}$ & $\mathrm{SH}$ & $\begin{array}{l}\text { SN, ST, TH, BW, BY, BE, BB, HB, } \\
\text { HH, HE, MV, NI, NW, RP, SL }\end{array}$ \\
\hline April $28^{\text {th }}$ & $\mathrm{SH}$ & $\begin{array}{l}\text { SN, ST, TH, BW, BY, BE, BB, HB, } \\
\text { HH, HE, MV, NI, NW, RP, SL }\end{array}$ \\
\hline April $29^{\text {th }}$ & & $\begin{array}{l}\mathrm{SN}, \mathrm{ST}, \mathrm{TH}, \mathrm{BW}, \mathrm{BY}, \mathrm{BE}, \mathrm{BB}, \mathrm{HB}, \\
\mathrm{HH}, \mathrm{HE}, \mathrm{MV}, \mathrm{NI}, \mathrm{NW}, \mathrm{RP}, \mathrm{SL}, \mathrm{SH}\end{array}$ \\
\hline
\end{tabular}

Compulsory face mask policies appear to be widely supported by the German public. Nation-

\footnotetext{
${ }^{3}$ Fines of varying amounts are in place in Baden-Wuerttemberg, Bavaria, Berlin, Hamburg, Hesse, Lower Saxony, Mecklenburg-West Pomerania, North Rhine-Westphalia and Rhineland-Palatinate. In some cases (e.g. North Rhine-Westphalia), fines vary within the state and are enforced at the discretion of local councils.
} 
ally representative survey data suggest that, before the first state-wide introduction in late April 2020, compulsory face mask policies were supported by $86 \%$ of the population [BfR, 2020]. More than one month into the nation-wide face mask requirement, support remains high at 79\% [BfR, 2020]. The YouGov Covid 19 Behaviour Tracker provides nationally representative data on reported face mask use in Germany during April and May 2020 [YouGov, 2020]. The number of individuals who report always wearing masks in public spaces (public transport, supermarkets, shops or main roads) was $11 \%$ on April $2^{\text {nd }}$ and $16 \%$ on April $15^{\text {th }}$. Reported mask use increased sharply, to $26 \%$, on April $24^{\text {th }}$, as first compulsory face mask policies were enacted. On April $30^{\text {th }}$, when face masks were compulsory across the country, $56 \%$ reported always wearing masks in public, increasing further to over $60 \%$ in May. As these data are self-reported and likely suffer from social desirability bias, we expect these to be upper-bound estimates of face mask use. As far as we are aware, there are no nationally representative data on actual face mask use. Evidence from a field experiment carried out in Berlin in mid-April $(\mathrm{N}=300)$ found that only $17 \%$ of people were wearing face masks in stores, supermarkets or post-offices [Seres et al., 2020]. These estimates are substantially lower than what is self-reported in Berlin (26\% for the same time period and $48 \%$ for the following week), although self-reported data are not representative at the state-level.

Several factors could explain why some states implemented compulsory face mask policies earlier than others. First, one could see the staggered introduction as a process of bottom-up policy diffusion. For example, Thuringia implemented a state-wide compulsory face mask policy around two weeks after its second-largest city, Jena, became the first city in Germany to require face masks in public spaces [Der Spiegel, 2020]. The federal government largely took a back seat and continued to recommend voluntary face mask use, even as several states had already introduced compulsory measures [Bundesregierung, 2020]. A second interpretation is that variation in the supply of face masks, and concerns about compulsory face masks leading to panic-buying, played a role. For example, the governments of Bavaria, Lower Saxony and North Rhine-Westphalia initially resisted moves to introduce compulsory 
face masks on these grounds [DW, 2020, Nordbayerischer Kurier, 2020, Aachener Zeitung, 2020]. Third, geographic variation in transmission rates could have prompted some cities (and states) to move earlier than others. For example, Jena was considered a COVID-19 "hotspot" before it introduced compulsory face masks [MDR, 2020].

Even though some evidence from the US suggests that party ideology is associated with support for face masks [Pepinsky, 2020], this does not appear to be the case in Germany. For instance, Jena is governed by a mayor from the liberal FDP. The first state to implement compulsory face masks (Saxony) is governed by the centre-right $C D U$ (in coalition with the left-wing $S P D$ and the Greens), while another early mover (Thuringia) is governed by the left-wing Die Linke (also in coalition with the SPD and the Greens).

\section{Data and methods}

\subsection{Data}

To measure community mobility, we use the publicly available Google COVID-19 Community Mobility Reports for Germany. ${ }^{4}$ These data capture daily changes in mobility patterns in each German state based on GPS data from Google Account users who have opted-in to the Location History feature. We use mobility data from the period between March $23^{\text {rd }}$ and May $21^{\text {st }}$. We exclude observations from before the national lock-down (which was announced on March $22^{\text {nd }}$ and came into force the day after), as mobility reduced drastically in the preceding days, which could distort our estimates (see Figure 1 below).

Google's COVID-19 Community Mobility Reports are disaggregated by place categories. The data capture the number of visits to groceries and pharmacies (grocery markets and food shops, food warehouses, farmers markets, drug stores, and pharmacies), transit stations

\footnotetext{
${ }^{4}$ Available at: https://www.google.com/covid19/mobility/
} 
(transportation hubs including subway, bus, and train stations), parks (local and national parks, beaches, marinas, public gardens) and retail and recreation (restaurants, cafes, theme parks, shopping centres, museums, libraries and cinemas) [Aktay et al., 2020]. The data also capture mobility patterns for places of work and residence. For workplaces, Google uses the relative frequency of visits, as well as time and duration to calculate how many individuals spent more than one hour at their place of work [Aktay et al., 2020]. A similar process is used to calculate the number of hours spent in places of residence [Aktay et al., 2020].

For each day, the data record the percentage change in the number of visits (or length of stay) relative to a baseline value for that day of the week. This baseline is the median value for the corresponding day of the week in the five-week period between January $3^{\text {rd }}$ and February $6^{\text {th }} 2020 .^{5}$ The data aggregation process is similar the one used to create "popular times" for places in Google Maps. Observations that do not meet Google's required privacy thresholds are coded as missing by Google (in our study period this is the case for mobility in groceries and pharmacies on three Sundays in Berlin). Importantly, these data are based on Google Account users who opted-in to the Location History feature. This means that the data are not necessarily representative of the German population.

We focus on mobility in public spaces, captured by the percentage change in the number of visits to (or time spent in) groceries and pharmacies $(G P)$, workplaces $(W)$ and transit stations $(T)$. The main outcome of interest is the percentage change in average community mobility in public spaces, equal to $\frac{G P+W+T}{3}$, relative to the baseline. We also use the percentage change in the number of hours spent at home relative to the baseline as an additional catch-all measure. For the sake of simplicity, we use the terms "mobility patterns" or "mobility", to refer to percentage change in the number of visits to (or time spent in) public spaces or number of hours spent at home.

\footnotetext{
${ }^{5}$ This means there are $7 \times 16$ baseline values, one for each state and day of the week. Google does not provide data on the baseline total count/number (visits, hours spent), but only percentage changes relative to the (unknown) baseline. We address this issue by including state*day-of-the-week fixed effects in our model specification (see Section 3.3)
} 
We would like to highlight that the Google data can be used to measure community mobility patterns, but do not provide a good measure of social distancing, as implied in several recent studies [Wellenius et al., 2020, Schrimpf et al., 2020, Ansell, 2020]. The term "social distancing" refers to the physical (Euclidean) distance between two people [CDC, 2020b], which is not directly captured by the Google mobility data. Even though it is plausible that once mobility (i.e. number of visits to public spaces) reaches a certain level, social distancing will be harder to maintain in some locations, it is unclear how this can be accurately inferred from the data.

Google also provides mobility data on parks as well as retail and recreation. However, these locations are less relevant for our analysis. This is because some places that fall within the park category are arguably not relevant for the spread of COVID-19 (for instance national parks, where the risk of transmission is likely extremely low). We also do not consider retail and recreation, given that for most of the study period, the places that fall into this category (e.g. restaurants, cafes or cinemas) were required to close.

To create a timeline for when German states introduced compulsory face mask policies, we consulted state-specific secondary legislation (Verordnungen), which are typically published on states' official websites. We also extracted information from the German Catalogue of Fines ${ }^{6}$ (Bußgeldkatalog), which records penalties for not wearing face masks in different states, as well as from official announcements made to national and local newspapers. Through the same process, we identified when states implemented other important policies related to the COVID-19 pandemic that could also affect community mobility patterns. We systematically extracted information on the re-opening of schools and shops, as well as the official start and end of state-specific stay-at-home orders (Ausgangsbeschraenkungen).

Finally, we obtain the daily number of new confirmed COVID-19 cases in each state from the

\footnotetext{
${ }^{6}$ Available at: https://www.bussgeldkatalog.org/corona/
} 
Robert Koch Institute (RKI) ${ }^{7}$ which is the German federal government agency responsible for disease control and prevention. We use RKI data corresponding to our study period (March $23^{\text {rd }}$ to May $21^{\text {st }}$ ).

\subsection{Mobility trends}

Figure 1 provides a descriptive overview of changes in average mobility in public spaces (groceries and pharmacies, workplaces and transit stations). It shows that mobility in public spaces in Germany decreased substantially in the period leading up to the national-level lock-down on March 23 $3^{\text {rd }}$ 2020. As shown in Appendix B, similar patterns can be observed for mobility trends in each state and in specific public spaces (separately for groceries and pharmacies, workplaces and transit station). The number of hours spent in places of residence increased over the same time period, although changes appear less drastic, as individuals already spend a large proportion of their time at home.

\footnotetext{
${ }^{7}$ Available at: https://npgeo-corona-npgeo-de.hub.arcgis.com/
} 
Figure 1: Average mobility in public spaces in Germany

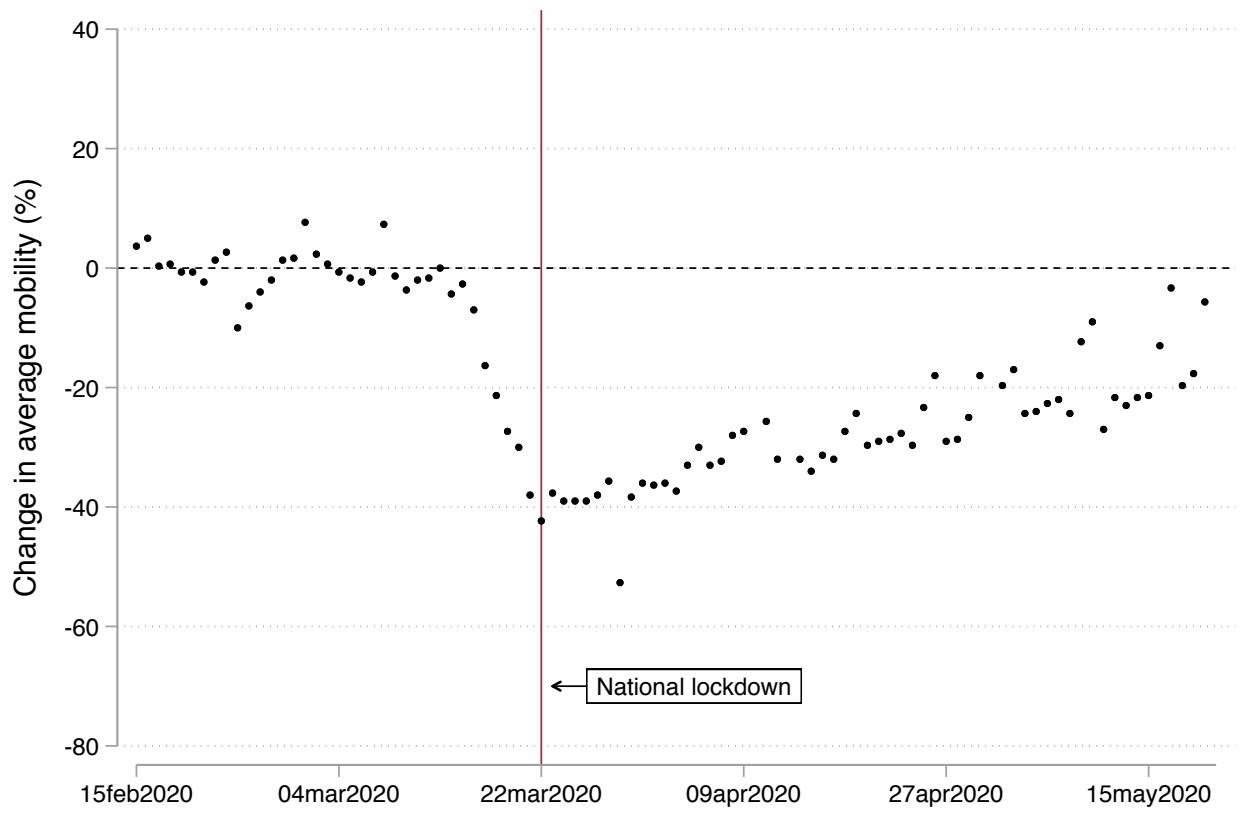

Note: This graph shows the percentage change in average mobility in public spaces (groceries and pharmacies, workplaces, and transit stations) for each day between Feb $15^{\text {th }}$ and May $21^{\text {st }} 2020$ relative to the baseline. The baseline is the median value for the corresponding day of the week in the five-week period between Jan $3^{\text {rd }}$ and Feb $6^{\text {th }}$ 2020. Data: Google COVID-19 Community Mobility Reports.

\subsection{Methods}

To isolate the causal effect of compulsory face mask policies, we use a generalised differencein-differences (DD) design that exploits the staggered introduction of compulsory face mask policies in German states. Intuitively, the DD approach isolates the effect of a policy by comparing changes in outcomes before and after an intervention for a treatment and control group. An attractive feature of the DD approach is that it can account for unobserved time-invariant confounders that differ between states (e.g. health system characteristics) as well as for unobserved time trends shared across states (e.g. national public holidays) [Kreif et al., 2016, Wing et al., 2018]. In this setup, all units are eventually "treated" (i.e. all states implement a compulsory face mask policy), but at different times. 
We first use a static DD model:

$$
Y_{s t}=\alpha_{s}+\beta_{t}+\gamma D_{s t}+X_{s t}^{\prime}+\eta_{0}+\epsilon_{s t}
$$

where $Y_{s t}$ is a measure of community mobility, $D_{s t}$ is a treatment indicator equal to one for states and dates where compulsory face mask policies are in place and zero otherwise, ${ }^{8}$ $\alpha_{s}$ denotes state-level fixed effects, $\beta_{t}$ denotes date fixed effects, and $X_{s t}^{\prime}$ is a vector of time-varying state-specific controls. The controls are state-specific public holidays (Tag des Sieges in Berlin), an indicator for when states relaxed their stay-at-home orders (Ausgangsbeschraenkungen), the daily new confirmed COVID-19 cases in each state (lagged by one day), an indicator for when states re-opened secondary schools for final year classes, an indicator for when states allowed retail shops $<800 \mathrm{~m}^{2}$ to re-open, an indicator for when states allowed retail shops to re-open without any size restrictions, and state*day-of-theweek fixed effects. $\eta_{0}$ is a constant, and $\epsilon_{s t}$ is an error term. The coefficient of interest is $\gamma$, which identifies the effect of compulsory mask policies on community mobility under the parallel trends assumption (i.e. that community mobility trends in treated and untreated states would have developed in parallel in the absence of compulsory face mask policies). We assess the plausibility of the parallel trends assumption by inspecting pre-treatment trends in a "fully dynamic" event study framework (see Equation 2 below).

Given that the static DD estimates can be biased when treatment effects vary over time [Goodman-Bacon, 2018], we use an event study approach that allows us to examine the effect of the policy for the days before and after implementation. In the main event study specification, the data are trimmed so that the panel is balanced in time periods (days) relative to the treatment, as recommended by Abraham and Sun [2018]. Schleswig-Holstein is the last state to receive treatment on April $29^{\text {th }}$ and Google mobility data are available up until May $21^{\text {st }}$. Our "trimmed" panel therefore contains 22 days before and 22 days after

\footnotetext{
${ }^{8}$ For Berlin, we code $D_{s t}=1$ following the introduction of compulsory face masks in public transport on April $27^{\text {th }}$. The policy was extended to shops two days later.
} 
the treatment date in each state.

To investigate pre-trends, we use a "fully dynamic" event study model, which is specified as follows:

$$
Y_{s t}=\alpha_{s}+\beta_{t}+\sum_{\ell=-21}^{-2} \gamma_{\ell} D_{s t}^{\ell}+\sum_{\ell=0}^{22} \gamma_{\ell} D_{s t}^{\ell}+X_{s t}^{\prime}+\epsilon_{s t}
$$

where $D_{s t}^{\ell}=\mathbf{1}\left\{t-E_{s}=\ell\right\}$ is a "switch-on switch-off" indicator for unit $s$ being periods $\ell$ away from the initial treatment period $E_{s}$ at calendar time $t$. In the trimmed specification, distant relative periods (where $|\ell|>22$ ) are excluded so that the panel is balanced in periods relative to the treatment. Furthermore, the first and last treatment lead are set to zero to address under-identification in the fully dynamic model [Borusyak and Jaravel, 2017].

To asses how treatment effects change over time, we instead use a "semi-dynamic" event study model, where all leads are set to zero - following Borusyak and Jaravel [2017]. This specification is robust to event-time treatment effect heterogeneity. Furthermore, it estimates dynamic treatment effects more efficiently than the fully-dynamic model Borusyak and Jaravel [2017]. The semi-dynamic model is specified as follows:

$$
Y_{s t}=\alpha_{s}+\beta_{t}+\sum_{\ell=0}^{22} \gamma_{\ell} D_{s t}^{\ell}+X_{s t}^{\prime}+\epsilon_{s t}
$$

All models are estimated using OLS with robust standard errors clustered at the state level. We also use a wild cluster bootstrap procedure to obtain more accurate p-values [Roodman et al., 2019]. This is advisable given that in a setting with few clusters (16 states) the standard cluster-robust variance estimator may lead to over-rejection of the null and confidence intervals that are too narrow [Bertrand et al., 2004, Cameron et al., 2008]. We 
report bootsrapped p-values in the main results table and refer to Appendix F.3 for more details on the bootstrap procedure.

\section{Results}

\subsection{Effect of compulsory face masks on mobility in public spaces}

We first present results from our static DD specification (Equation 1) which investigates the average effect of introducing compulsory face mask policies on community mobility. As shown in Table 2, we do not find evidence to suggest that compulsory face mask policies affect average mobility in public spaces. Overall, the estimated effects are not statistically significant and relatively small in magnitude, lying between -0.8 percentage points $(-0.05$ SD) and -1.8 percentage points (-0.11 SD). Column 5 shows results for our preferred model specification, which includes state and date fixed effects and a broad range of state-specific controls: public holidays, the daily number of new COVID-19 cases in each state (lagged by one day), and several policy changes that are likely to affect community mobility (lock-down rules being relaxed, secondary schools and retail re-opening). The main treatment effect is quite precisely estimates and we can rule out even small increases in mobility that are larger than $0.03 \mathrm{SD}$.

Column 6 shows results for a more flexible model, which also includes an interaction between day-of-the-week and state fixed effects. In contrast to all other models, the model suggests a significant negative effect of -1.8. Our sense is that this is because this static model heavily weighs changes occurring shortly after the treatment - an issue we examine further in the next section. 
Table 2: Effect of compulsory face mask policies on mobility in public spaces

\begin{tabular}{|c|c|c|c|c|c|c|}
\hline & $(1)$ & $(2)$ & $(3)$ & $(4)$ & $(5)$ & $(6)$ \\
\hline Face mask policy & $\begin{array}{l}-0.759 \\
(0.703) \\
{[0.333]}\end{array}$ & $\begin{array}{l}-1.075 \\
(0.692) \\
{[0.211]}\end{array}$ & $\begin{array}{l}-1.074 \\
(0.700) \\
{[0.214]}\end{array}$ & $\begin{array}{l}-1.591 \\
(0.946) \\
{[0.199]}\end{array}$ & $\begin{array}{l}-1.500 \\
(0.924) \\
{[0.210]}\end{array}$ & $\begin{array}{c}-1.763^{* *} \\
(0.605) \\
{[0.027]}\end{array}$ \\
\hline State FE & $\checkmark$ & $\checkmark$ & $\checkmark$ & $\checkmark$ & $\checkmark$ & $\checkmark$ \\
\hline Date FE & $\checkmark$ & $\checkmark$ & $\checkmark$ & $\checkmark$ & $\checkmark$ & $\checkmark$ \\
\hline State-specific holidays & & $\checkmark$ & $\checkmark$ & $\checkmark$ & $\checkmark$ & $\checkmark$ \\
\hline Lockdown relaxed & & $\checkmark$ & $\checkmark$ & $\checkmark$ & $\checkmark$ & $\checkmark$ \\
\hline COVID-19 cases (t-1) & & & $\checkmark$ & $\checkmark$ & $\checkmark$ & $\checkmark$ \\
\hline Sec. school open & & & & $\checkmark$ & $\checkmark$ & $\checkmark$ \\
\hline Retail open & & & & & $\checkmark$ & $\checkmark$ \\
\hline State ${ }^{*}$ Day-of-week FE & & & & & & $\checkmark$ \\
\hline Observations & 960 & 960 & 960 & 960 & 960 & 960 \\
\hline R-squared & 0.965 & 0.973 & 0.973 & 0.973 & 0.973 & 0.985 \\
\hline Clusters & 16 & 16 & 16 & 16 & 16 & 16 \\
\hline
\end{tabular}

Appendix $\mathrm{C}$ shows results for specific public locations. We find that the introduction of compulsory face masks leads to a small but statistically significant reduction in mobility for visits to grocery stores and pharmacies of -4.9 percentage points or $-0.4 \mathrm{SD}$ (95\% CI between -0.28 and -0.10$)$. We also find evidence for a small increase in the number of hours spent at home of $0.08 \mathrm{SD}$ (95\% CI between $0.03 \mathrm{SD}$ and $0.13 \mathrm{SD}$ ). Our static models do not detect significant effects on mobility in workplaces and transit stations.

\subsection{Dynamic effects}

Next, we use event study models to assess parallel trends and examine how compulsory face masks affect mobility patterns over time. All models include controls from our preferred static DD model specification: state-specific public holidays, the daily number of new COVID-19 cases in each state (lagged by one day), and dummies for policy changes that 
likely affect community mobility (lock-down rules being relaxed, secondary schools and retail re-opening). In Appendix D, we present results from the fully dynamic specification (Equation 2), which allows us to assess the parallel trends assumption. The absence of apparent pre-treatment trends suggests that our identification strategy is valid.

We use the semi-dynamic specification (Equation 3) to investigate potential over-time effects of compulsory face mask policies - following Borusyak and Jaravel [2017]. Figure 2 below summarises the results from the semi-dynamic model. We do not find evidence to suggest that compulsory face mask policies affect mobility in public spaces over time. There is a significant decrease in mobility on the day compulsory face mask policies are introduced. This decrease is equal to -2.4 percentage points or -0.14 SD (95\% CI between -0.24 and -0.04), which is small in magnitude and comparable to the static DD estimate. We do not detect any significant effects on mobility for any other days following the policy change.

In Appendix E we examine over-time effects for mobility patterns in specific public spaces as well as time spent at home. We find that mobility in grocery shops and pharmacies decreases by between -7.7 percentage points $(-0.31 \mathrm{SD})$ and -2.2 percentage points $(-0.1 \mathrm{SD})$ within the first five days of the policy change, which is consistent with static DD estimates. This effect, however, fades out over time. We find only sporadic evidence for a positive over-time effect on mobility in places of work (for instance, a 2.8 percentage point $(0.15 \mathrm{SD})$ increase on the $3^{\text {rd }}$ day following the change, and a 3.6 percentage point $(0.19 \mathrm{SD})$ increase on the $4^{\text {th }}$ day). However, point estimates are imprecise and rarely distinguishable from zero. In terms of hours spent at home, we find a small increase within the first four days (between 0.14 and $0.17 \mathrm{SD}$ ), but no longer-term effects. We find no significant effects on mobility patterns in transit hubs. Overall, the results suggest that compulsory face mask policies only affect mobility in the very short term, with no detectable medium-term effects. 
Figure 2: Semi-dynamic event study estimates

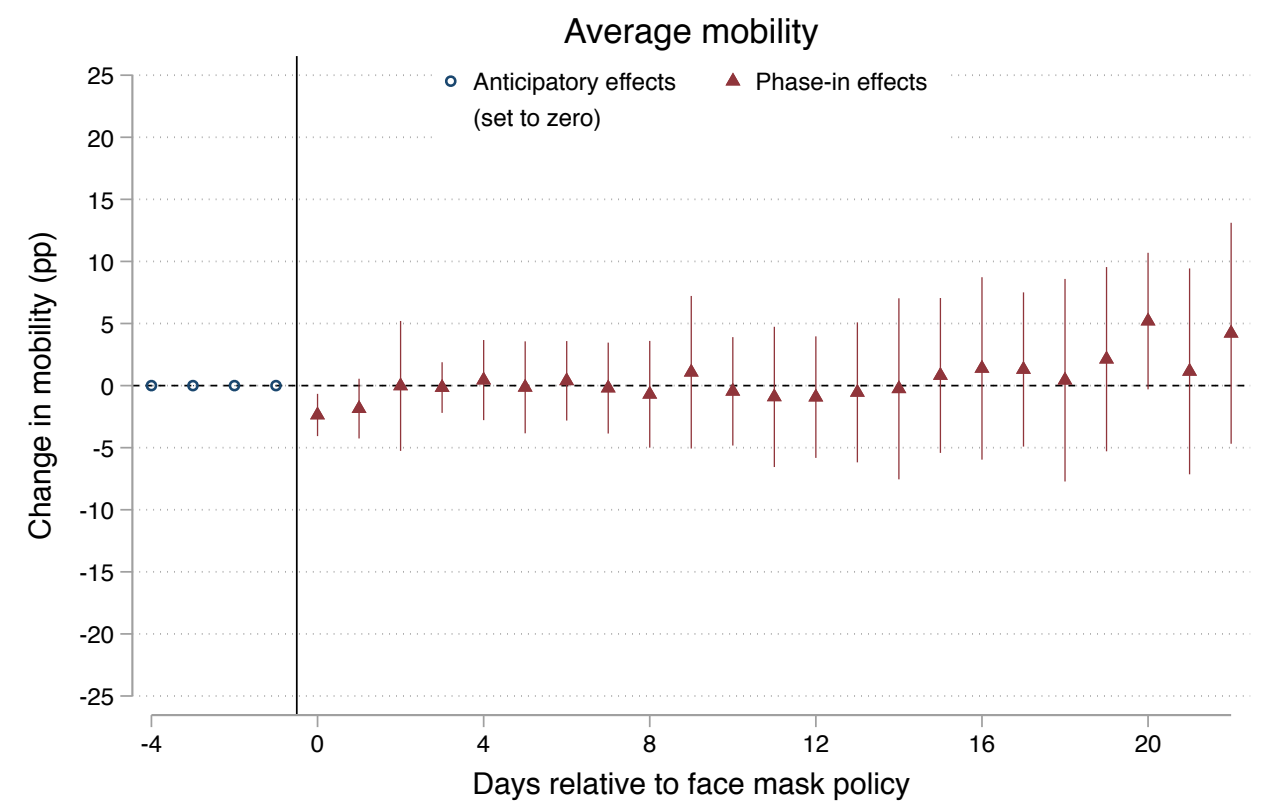

Note: This graph shows the estimated over-time effect of compulsory face mask policies on average mobility in public spaces (groceries and pharmacies, workplaces, and transit stations) for 22 days after the policy change. Point estimates are obtained from a semidynamic event study model, where all treatment leads are set to zero and the panel is "trimmed" such that it is balanced in time periods (days) relative to the policy change. The model includes controls from our preferred static DD model specification: state-specific public holidays, the daily number of new COVID-19 cases in each state (lagged by one day), and dummies for several policy changes that are likely to affect community mobility (lock-down rules being relaxed, secondary schools and retail reopening). Vertical lines represent cluster-robust 95\% confidence intervals.

\subsection{Robustness checks}

We conduct a number of robustness checks. First, we run the fully-dynamic specification using a "binning" approach [Abraham and Sun, 2018], where we replace the first and last switch-on-switch-off leads and lags with switch-on-stay-on indicators (see Equation 4). As shown in Appendix F.1, the main results hold using this alternative event study specification.

Second, we address the potential problem of negative weighting in the static DD setup by using a control group of states that are never exposed to the treatment, but plausibly face the same time effects as the treatment group [Borusyak and Jaravel, 2017]. To this end, 
we drop all observations from April $27^{\text {th }}$ onward. The three states that made face masks compulsory before April $27^{\text {th }}$ now constitute the treatment group and the remaining thirteen states are part of the never-treated control group. As shown in Appendix F.2, we also do not find evidence that compulsory face masks affect community mobility using this alternative specification.

Third, we address the potential concern that our null-results are an artefact of too-few clusters [MacKinnon and Webb, 2018]. We show that the main results hold when using a "sub-cluster" wild bootstrap procedure (see Appendix F.3) and robust standard errors clustered at the state-week level (see Appendix F.4).

Finally, we use a synthetic control design, which, similar to the DD design, compares differences in mobility patterns between treated and untreated states before and after the policy change. However, in contrast to the DD design, the synthetic control design does not give equal weight to all untreated states but generates a weighted average (a synthetic control) that closely matches a treated state over the pre-treatment period [Kreif et al., 2016, Abadie et al., 2010]. In Appendix F.5 we show that post-treatment mobility patterns do not differ significantly between the first state to implement compulsory face masks (Saxony) and its synthetic control. This is further evidence that compulsory face masks do not appear to affect community mobility.

\section{Discussion}

There is an ongoing debate about whether to introduce policies requiring the general public to wear protective face masks. A key concern is that individuals could feel safer as a result and, due to risk compensating behaviour, increase their mobility. This could undermine the most important public-health advice to contain the spread of COVID-19 - which is to reduce 
mobility and maintain social distancing [Greenhalgh et al., 2020]. We provide first empirical evidence on the impact of compulsory face mask policies on community mobility. We do not find evidence to suggest that, in Germany, compulsory face mask policies affect mobility in public spaces (groceries and pharmacies, workplaces and transit hubs).

When examining mobility in specific locations, we find a short-term reduction in the number of visits to groceries and pharmacies and a short-term increase in the number of hours spent at home (respectively within five and four days of the policy change). We find no significant over-time effects on mobility in workplaces and transit hubs. Our overall interpretation of the results is that compulsory face mask policies in Germany did not affect community mobility. We do not examine how compulsory face mask policies affect important individual behaviours such as hand-washing and social distancing. However, the findings presented here should to some degree alleviate policy makers' concerns about compulsory face mask policies leading to an increase in community mobility.

Even though compulsory face mask policies have been introduced in several countries, we currently lack systematic evidence on the effect of face masks on human behaviour. A recent small-scale field experiment implemented in Berlin before face mask became compulsory, finds that masks increase physical distancing by $9 \mathrm{~cm}$ on average [Seres et al., 2020] - thereby finding no evidence of risk compensating behaviour. The authors hypothesise that this is due to others perceiving face masks as a signal of a larger preferred physical distance by the wearer. Even though this signalling effect most likely disappears in a setting where face masks are compulsory, we also do not find evidence for risk compensation at the community level.

There are two potential mechanisms which could explain our main finding that compulsory face mask policies have no discernible effect on community mobility. First, it might be that there is simply no risk compensating behaviour when it comes to face masks. One reason for this might be that individuals estimate that the risk of contracting COVID-19 is high, or that 
face masks do not offer effective protection, which stands in contrast to other settings where risk compensation has been studied - for example, for vaccines (where perceived risks are relatively low and protection offered is high) [Kapoor, 2008]. Second, it might be that any risk compensation (which would increase mobility) is outweighed by increased salience or the hassle factor (which would decrease mobility). In terms of mobility in specific locations, we find a short-term negative effect on the number of visits to groceries and pharmacies - where face masks are required. Given that the effect occurs immediately and fades out very quickly, we believe that the hassle factor provides a better explanation than increased salience (where negative effects would arguably persist over time). This explanation has intuitive appeal. As face masks are uncomfortable to wear, individuals might initially make fewer visits to locations where face masks have to be worn, until they adapt to the new circumstances. One reason why we observe an effect for groceries and pharmacies but not for transit hubs might be that it is easier and less costly for individuals to change the frequency of visits to grocery shops, but that this is more difficult for transit. As we do not have access to individual-level data, we are unfortunately not in a position to test these hypotheses.

Our results are limited in three main respects. First, we are only able to observe the effect of compulsory face mask policies in the medium-term (up to three weeks after the policy change). It is possible that there are changes to community mobility in the long run that we are not able to detect. However, our results suggest that any changes in mobility fade out within days of the policy change and it is unclear if one would expect additional changes in behaviour after an initial adaptation. Second, one concern with the Google COVID19 Community Mobility Reports is that the data are based on Google Account users who opted-in to Google's Location History feature. It is therefore likely that these data are from a non-random sub-sample of the German population. Whilst we have no data on the number of people using this feature, Germany has very high smartphone penetration. Over $98 \%$ of people under 50 years of age and $80 \%$ on average use a smartphone, with Android as the main operating system [Statista, 2019]. An additional concern is that the accuracy and 
coverage of the data vary across sub-national units (e.g. between urban and rural areas) in a systematic manner.

Finally, whilst this paper provides important evidence for current policy debates on how to manage the COVID-19 pandemic, it is unclear if the results can be generalised to other settings. The Google mobility data used in this paper, or other sources of aggregate-level GPS data, could be used to determine the effect of compulsory face mask policies in other countries. Further research is also needed on the impact of compulsory face mask policies on other important behaviours such as hand washing and social distancing.

Acknowledgements: We would like to thank Aurélia Lépine, Cherry Law, Timothy PowellJackson, Henri Salokangas, Mika Kortelainen and Panu Poutvaara for their helpful comments.

Funding: This research did not receive any specific grant from funding agencies in the public, commercial, or not-for-profit sectors.

Declarations of interests: None.

Contributions: RK and MD jointly designed the study, conducted the analysis and wrote the first draft of the paper. JT provided guidance on the analysis and reviewed the paper. 


\section{References}

Aachener Zeitung. Medizinische Masken prioritär: Spahn und Laschet gegen Maskenpflicht in Deutschland, 2020. URL https://www.aachener-zeitung.de/nrw-region/ spahn-und-laschet-gegen-maskenpflicht-in-deutschland-aid-49847769.

Alberto Abadie, Alexis Diamond, Hainmueller, and Jens. Synthetic control methods for comparative case studies: Estimating the effect of California's Tobacco control program. Journal of the American Statistical Association, 105(490):493-505, 2010. ISSN 01621459. doi: 10.1198/jasa.2009.ap08746.

Sarah Abraham and Liyang Sun. Estimating Dynamic Treatment Effects in Event Studies With Heterogeneous Treatment Effects. SSRN Electronic Journal, 2018. doi: 10.2139/ ssrn.3158747. URL https://arxiv.org/abs/1804.05785.

Ahmet Aktay, Shailesh Bavadekar, Gwen Cossoul, John Davis, Damien Desfontaines, Alex Fabrikant, Evgeniy Gabrilovich, Krishna Gadepalli, Bryant Gipson, Miguel Guevara, Chaitanya Kamath, Mansi Kansal, Ali Lange, Chinmoy Mandayam, Andrew Oplinger, Christopher Pluntke, Thomas Roessler, Arran Schlosberg, Tomer Shekel, Swapnil Vispute, Mia Vu, Gregory Wellenius, Brian Williams, and Royce J Wilson. Google COVID-19 Community Mobility Reports: Anonymization Process Description (version 1.0). apr 2020. URL http://arxiv.org/abs/2004.04145.

Al Jazeera News. Which countries have made wearing face masks compulsory? - News - Al Jazeera, 2020. URL https://www.aljazeera.com/news/2020/04/ countries-wearing-face-masks-compulsory-200423094510867.html.

Hunt Allcott, Levi Boxell, Jacob Conway, Matthew Gentzkow, Michael Thaler, and David Y. Yang. Polarization and Public Health: Partisan Differences in Social Distancing during COVID-19. SSRN Electronic Journal, 2020. ISSN 0898-2937. doi: 10.2139/ssrn.3570274. URL https://www. nber .org/papers/w26946.

Soontae An. Antidepressant direct-to-consumer advertising and social perception of the prevalence of depression: Application of the availability heuristic. Health Communication, 23(6):499-505, nov 2008. ISSN 10410236. doi: 10.1080/10410230802342127.

Joshua D. Angrist and Jörn-Steffen Pischke. Mostly Harmless Econometrics. 2009. doi: 10.2307/j.ctvcm4j72. URL https://press.princeton.edu/books/paperback/ 9780691120355/mostly-harmless-econometrics.

Ben Ansell. What explains differences in social distancing in the UK? (April):1-15, 2020. URL https://tinyurl.com/yc4jd8y7.

M. Bertrand, E. Duflo, and S. Mullainathan. How Much Should We Trust Differences-InDifferences Estimates? The Quarterly Journal of Economics, 119(1):249-275, feb 2004. ISSN 0033-5533. doi: 10.1162/003355304772839588. URL https://academic .oup.com/ qje/article-lookup/doi/10.1162/003355304772839588.

BfR. BfR-Corona-Monitor - BfR, 2020. URL https://www.bfr.bund.de/de/ bfr-corona-monitor-244782.html.

K Borusyak and X Jaravel. Revisiting Event Study Designs. 2017. URL https://papers . ssrn.com/sol3/papers.cfm?abstract_id=2826228.

Guglielmo Briscese, Nicola Lacetera, Mario Macis, and Mirco Tonin. Compliance with 
COVID-19 Social-Distancing Measures in Italy: The Role of Expectations and Duration. Technical report, National Bureau of Economic Research, Cambridge, MA, mar 2020. URL http: //www . nber .org/papers/w26916.pdf.

Bundesregierung. Bundesregierung - Coronavirus in Deutschland — Sich selbst und andere Schützen, 2020. URL https://www.bundesregierung.de/breg-de/themen/ coronavirus/empfehlung-schutzmasken-1745224.

A. Cameron, Jonah B. Gelbach, and Douglas L. Miller. Bootstrap-based improvements for inference with clustered errors. Review of Economics and Statistics, 90(3):414-427, aug 2008. ISSN 00346535. doi: 10.1162/rest.90.3.414.

CDC. Use Cloth Face Coverings to Help Slow Spread - CDC, 2020a. URL https://www.cdc.gov/coronavirus/2019-ncov/prevent-getting-sick/ diy-cloth-face-coverings.html.

CDC. Social Distancing, Quarantine, and Isolation, 2020b. URL https://www.cdc.gov/ coronavirus/2019-ncov/prevent-getting-sick/social-distancing.html.

J Daoust, R Nadeau, R Dassonneville, E Lachapelle, E Bélanger, and J Savoie. How to survey citizens' compliance with COVID-19 public health measures? Evidence from three survey experiments. 2020. URL https://osf .io/preprints/socarxiv/gursd/.

Nabarun Dasgupta, Allison Lazard, Benjamin Eugene White, and Stephen W Marshall. Quantifying the social distancing privilege gap : a longitudinal study of smartphone movement. pages 0-13, 2020. URL https://www.medrxiv.org/content/10.1101/2020.05. $03.20084624 \mathrm{v} 1$.

Der Spiegel. Corona-Maskenpflicht in Jena: Die Stadt der schönen Muster DER SPIEGEL, 2020. URL https://www.spiegel.de/panorama/gesellschaft/ die-stadt-der-schoenen-muster-a-7a65406c-6b4e-4e8f-8734-483942e59d5d.

Die ZEIT. Corona-Lockerungen: Thüringen will Kontaktbeschränkung Mitte Juni beenden - ZEIT ONLINE, 2020. URL https://www.zeit.de/politik/deutschland/2020-05/ thueringen-kontaktverbot-corona-verordnung-lockerung.

Paul Dolan and Daniel Kahneman. Interpretations of Utility and Their Implications for the Valuation of Health. The Economic Journal, 118(525):215-234, jan 2008. ISSN 0013-0133. doi: 10.1111/j.1468-0297.2007.02110.x. URL https://academic.oup.com/ej/article/ $118 / 525 / 215-234 / 5088783$.

DW. Streit über Maskenpflicht gegen die Corona-Pandemie entbrannt - Aktuell Deutschland - DW - 31.03.2020, 2020. URL hhttps://tinyurl.com/ycw57j8d.

Shuo Feng, Chen Shen, Nan Xia, Wei Song, Mengzhen Fan, and Benjamin J. Cowling. Rational use of face masks in the COVID-19 pandemic. The Lancet Respiratory Medicine, 8(May):434-436, may 2020. ISSN 22132619. doi: 10.1016/S2213-2600(20)30134-X.

Sebastian Galiani and Brian Quistorff. The Synth_Runner Package: Utilities to Automate Synthetic Control Estimation Using Synth. The Stata Journal: Promoting communications on statistics and Stata, 17(4):834-849, dec 2017. ISSN 1536-867X. doi: 10.1177/1536867X1801700404. URL http://journals . sagepub.com/doi/10.1177/ $1536867 X 1801700404$.

Susan Godlonton, Alister Munthali, and Rebecca Thornton. Responding to risk: Circumcision, information, and HIV prevention. Review of Economics and Statistics, 98(2):333-349, 
may 2016. ISSN 15309142. doi: 10.1162/REST_a_00516.

Andrew Goodman-Bacon. Difference-in-Differences with Variation in Treatment Timing. National Bureau of Economic Research, 2018. ISSN 0898-2937. doi: 10.3386/w25018. URL https://www .nber.org/papers/w25018.pdf.

Trisha Greenhalgh, Manuel B. Schmid, Laurence Gruer, Thomas Czypionka, Dirk Bassler, and Laurence Gruer. Face masks for the public during the covid-19 crisis. The BMJ, 369 (April):1-4, apr 2020. ISSN 17561833. doi: 10.1136/bmj.m1435. URL https://www. bmj . com/content/369/bmj .m1435.

The Guardian. German state causes alarm with plans to ease lockdown measures - World news - The Guardian, 2020. URL https://tinyurl.com/y83mbz3v.

IMF. World Economic Outlook, April 2020: The Great Lockdown. Technical Report April, 2020. URL https://www.imf.org/en/Publications/WEO/Issues/2020/04/14/ weo-april-2020.

Frederik Jørgensen, Alexander Bor, and Michael Bang Petersen. Compliance Without Fear: Predictors of Protective Behavior During the First Wave of the COVID-19 Pandemic. 2020. URL https://psyarxiv. com/uzwgf.

Shailendra Kapoor. The HPV Vaccine and Behavioral Disinhibition, jan 2008. ISSN 1054139X.

Noémi Kreif, Richard Grieve, Dominik Hangartner, Alex James Turner, Silviya Nikolova, and Matt Sutton. Examination of the Synthetic Control Method for Evaluating Health Policies with Multiple Treated Units. Health Economics, 25(12):1514-1528, dec 2016. ISSN 10579230. doi: 10.1002/hec.3258. URL http://doi.wiley.com/10.1002/hec.3258.

Y. Li, H. Tokura, Y. P. Guo, A. S.W. Wong, T. Wong, J. Chung, and E. Newton. Effects of wearing N95 and surgical facemasks on heart rate, thermal stress and subjective sensations. International Archives of Occupational and Environmental Health, 78(6):501-509, jul 2005. ISSN 03400131. doi: 10.1007/s00420-004-0584-4.

James G. MacKinnon and Matthew D. Webb. The wild bootstrap for few (treated) clusters. The Econometrics Journal, 21(2):114-135, jun 2018. ISSN 1368-4221. doi: 10.1111/ectj. 12107. URL https://academic.oup.com/ectj/article/21/2/114-135/5078969.

MDR. Quarantäne und Mundschutz: Keine Corona-Neuinfektionen in Jena - MDR.DE, 2020. URL https://tinyurl.com/y9npkp3n.

Thomas Mellan, H Hoeltgebaum, S Mishra, C Whittaker, and et al. Report 21 - Estimating COVID-19 cases and reproduction number in Brazil. Technical report, 2020. URL https://www.imperial.ac.uk/mrc-global-infectious-disease-analysis/ covid-19/report-21-brazil/.

Ted R. Miller and Glenn C. Blomquist. The Regulation of Motor Vehicle and Traffic Safety, volume 56. 1989. ISBN 9789401077101. doi: 10.2307/1059086.

Nordbayerischer Kurier. Corona-Maßnahmen: SPD-Ministerpräsident erwartet baldige Maskenpflicht - Deutschland und Welt -Nordbayerischer Kurier, 2020. URL https: //tinyurl.com/y8n4w52m.

Sam Peltzman. The effects of automobile safety regulation: Reply. Accident Analysis and Prevention, 8(2):139-142, 1976. ISSN 00014575. doi: 10.1016/0001-4575(76)90005-1. URL https://www.jstor.org/stable/1830396. 
Tom Pepinsky. Yes, Wearing a Mask is Partisan Now, 2020. URL https://tompepinsky . com/2020/05/13/yes-wearing-a-mask-is-partisan-now/.

RKI. Coronavirus Disease 2019 (COVID-19) Daily Situation Report of the Robert Koch Institute. Technical report, 2020. URL https://corona.rki.de.

David Roodman, Morten Ørregaard Nielsen, James G. MacKinnon, and Matthew D. Webb. Fast and wild: Bootstrap inference in Stata using boottest. The Stata Journal: Promoting communications on statistics and Stata, 19(1):4-60, mar 2019. ISSN 1536-867X. doi: 10.1177/1536867X19830877. URL http://journals.sagepub.com/doi/10.1177/ $1536867 X 19830877$.

Paul Schrimpf, Hiroyuki Kasahara, and Victor Chernozhukov. Causal impact of masks, policies, behavior on early COVID-19 pandemic in the U.S. Technical report, Centre for Microdata Methods and Practice (cemmap), may 2020. URL https://www.ifs.org.uk/ publications/14863.

Gyula Seres, Anna Balleyer, Nicola Cerutti, Anastasia Danilov, Jana Friedrichsen, and Yiming Liu. Face Masks Increase Compliance with Physical Distancing Recommendations During the COVID-19 Pandemic. 2020. URL https://osf.io/db8sj/.

Ned Stafford. Covid-19: Why Germany's case fatality rate seems so low, apr 2020. URL https://www.bmj.com/content/369/bmj.m1395.

Statista. Smartphone penetration by age group in Germany 2019 — Statista, 2019. URL https://tinyurl.com/yc6t78w2.

The Guardian. Across the world, face masks are becoming mandatory. Why not in the UK? - Babak Javid - Opinion - The Guardian, 2020a. URL https://www.theguardian.com/commentisfree/2020/apr/24/ face-masks-mandatory-spread-coronavirus-government.

The Guardian. Do face coverings reduce risk and spread of coronavirus? - Transport - The Guardian, 2020b. URL https://www. theguardian.com/uk-news/2020/jun/04/ do-face-coverings-reduce-risk-and-spread-of-coronavirus?

The Guardian. Covid-19 track and trace: what can UK learn from countries that got it right? - World news — The Guardian, 2020c. URL https://www.theguardian.com/world/2020/may/21/ covid-19-track-and-trace-what-can-uk-learn-from-countries-got-it-right.

Joop Van Der Pligt and Nanne K. De Vries. Expectancy-value models of health behaviour: The role of salience and anticipated affect. Psychology and Health, 13(2):289-305, 1998. ISSN 08870446. doi: 10.1080/08870449808406752. URL https : //www. tandfonline.com/ action/journalInformation?journalCode=gpsh20.

Ian Walker. Drivers overtaking bicyclists: Objective data on the effects of riding position, helmet use, vehicle type and apparent gender. Accident Analysis and Prevention, 39(2): 417-425, mar 2007. ISSN 00014575. doi: 10.1016/j.aap.2006.08.010.

Gregory A. Wellenius, Swapnil Vispute, Valeria Espinosa, Alex Fabrikant, and Thomas C. Tsai. Impacts of State-Level Policies on Social Distancing in the United States Using Aggregated Mobility Data during the COVID-19 Pandemic. Harvard Global Health Institute, Cambridge, MA, 2020.

WHO. When and how to use masks, 2020. URL https://www.who. 
int/emergencies/diseases/novel-coronavirus-2019/advice-for-public/ when-and-how-to-use-masks.

Coady Wing, Kosali Simon, and Ricardo A. Bello-Gomez. Designing Difference in Difference Studies: Best Practices for Public Health Policy Research. Annual Review of Public Health, 39(1):453-469, apr 2018. ISSN 0163-7525. doi: 10.1146/ annurev-publhealth-040617-013507.

YouGov. Personal measures taken to avoid COVID-19, 2020. URL https: //yougov.co.uk/topics/international/articles-reports/2020/03/17/ personal-measures-taken-avoid-covid-19. 


\section{Online Appendix}

\section{A Implementation dates}

Table A1: Implementation dates of compulsory face mask policies and other COVID-19 measures

\begin{tabular}{lcccccc}
\hline State & Face mask policy & Lockdown relaxed & Sec. school open & Retail open $<800 \mathrm{~m}^{2}$ & All retail open & Restaurants open \\
\hline Baden-Wuerttemberg & $27 / 04 / 2020$ & $11 / 05 / 2020$ & $04 / 05 / 2020$ & $20 / 04 / 2020$ & $11 / 05 / 2020$ & $18 / 05 / 2020$ \\
Bayern & $27 / 04 / 2020$ & $06 / 05 / 2020$ & $27 / 04 / 2020$ & $27 / 04 / 2020$ & $11 / 05 / 2020$ & $18 / 05 / 2020$ \\
Berlin & $27 / 04 / 2020$ & $09 / 05 / 2020$ & $27 / 04 / 2020$ & $22 / 04 / 2020$ & $09 / 05 / 2020$ & $15 / 05 / 2020$ \\
Brandenburg & $27 / 04 / 2020$ & $09 / 05 / 2020$ & $27 / 04 / 2020$ & $22 / 04 / 2020$ & $09 / 05 / 2020$ & $15 / 05 / 2020$ \\
Bremen & $27 / 04 / 2020$ & $13 / 05 / 2020$ & $27 / 04 / 2020$ & $20 / 04 / 2020$ & $13 / 05 / 2020$ & $18 / 05 / 2020$ \\
Hamburg & $27 / 04 / 2020$ & $13 / 05 / 2020$ & $27 / 04 / 2020$ & $20 / 04 / 2020$ & $13 / 05 / 2020$ & $13 / 05 / 2020$ \\
Hessen & $27 / 04 / 2020$ & $09 / 05 / 2020$ & $27 / 04 / 2020$ & $20 / 04 / 2020$ & $09 / 05 / 2020$ & $15 / 05 / 2020$ \\
Nieder-Sachsen & $27 / 04 / 2020$ & $11 / 05 / 2020$ & $27 / 04 / 2020$ & $20 / 04 / 2020$ & $11 / 05 / 2020$ & $11 / 05 / 2020$ \\
Mecklenburg-Vorpommen & $27 / 04 / 2020$ & $11 / 05 / 2020$ & $27 / 04 / 2020$ & $20 / 04 / 2020$ & $02 / 05 / 2020$ & $09 / 05 / 2020$ \\
Nordrhein-Westphalen & $27 / 04 / 2020$ & $11 / 05 / 2020$ & $23 / 04 / 2020$ & $20 / 04 / 2020$ & $11 / 05 / 2020$ & $11 / 05 / 2020$ \\
Rheinland-Pfalz & $27 / 04 / 2020$ & $13 / 05 / 2020$ & $27 / 04 / 2020$ & $20 / 04 / 2020$ & $04 / 05 / 2020$ & $13 / 05 / 2020$ \\
Saarland & $27 / 04 / 2020$ & $28 / 04 / 2020$ & $04 / 05 / 2020$ & $20 / 04 / 2020$ & $04 / 05 / 2020$ & $18 / 05 / 2020$ \\
Sachsen & $20 / 04 / 2020$ & $20 / 04 / 2020$ & $20 / 04 / 2020$ & $20 / 04 / 2020$ & $15 / 05 / 2020$ & $15 / 05 / 2020$ \\
Sachsen-Anhalt & $23 / 04 / 2020$ & $04 / 05 / 2020$ & $23 / 04 / 2020$ & $20 / 04 / 2020$ & $04 / 05 / 2020$ & $18 / 05 / 2020$ \\
Schleswig-Holstein & $29 / 04 / 2020$ & $09 / 05 / 2020$ & $27 / 04 / 2020$ & $20 / 04 / 2020$ & $09 / 05 / 2020$ & $18 / 05 / 2020$ \\
Thueringen & $24 / 04 / 2020$ & $13 / 05 / 2020$ & $27 / 04 / 2020$ & $24 / 04 / 2020$ & $04 / 05 / 2020$ & $15 / 05 / 2020$ \\
\hline
\end{tabular}

Note: Berlin made face masks compulsory on public transport on April 27 and in shops two days later.All other states made face masks compulsory on public transport and shops at the same time. Face mask policy refers to the first date when a state implemented a compulsory face mask policy (regardless of whether it applied to public transport, shops, or both). Lockdown relaxed refers to the first date when a state introduced a first easing of the stay-at-home orders ("Ausgangsbeschränkungen"), which varied somewhat between different states. Secondary school open refers to the first date when a state re-opened secondary schools for pupils in their final year ("Abschlussklassen"). The two Retail open columns record the first date where a state allowed retail shops $<800 \mathrm{~m}^{2}$ and without any size restrictions to re-open. Restaurants open refers to the first date when a state allowed restaurants to re-open. Sources: Verordnungen der Landesregierungen, Bußgeldkatalog, national and local newspapers. 


\section{B Mobility trends}

Figure A1: Mobility trends in Germany (other mobility measures)
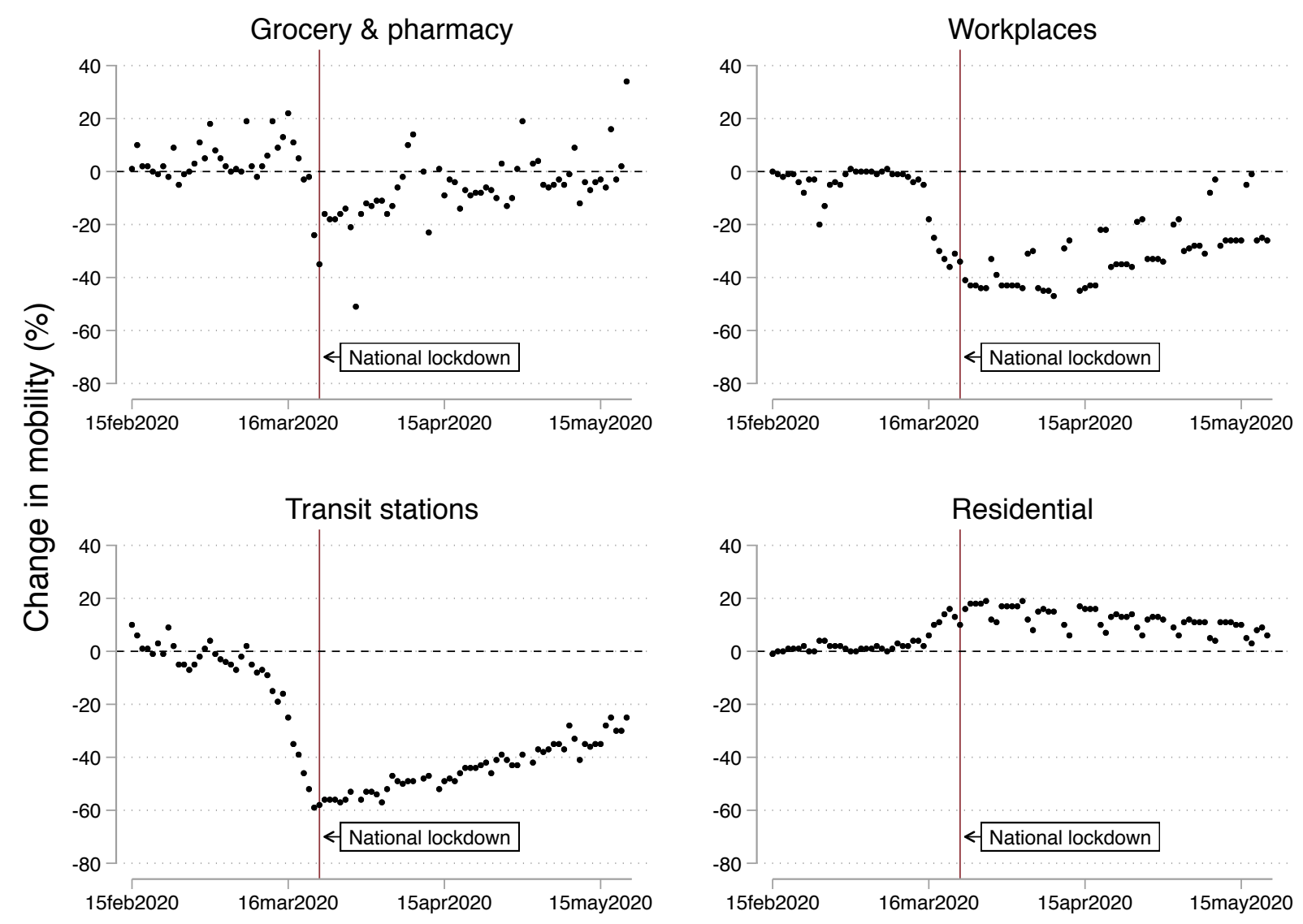

Note: This graph shows the percentage change in mobility (shown separately for goceries and pharmacies, workplaces, places of residence, and transit stations) for each day between February $15^{\text {th }}$ and May $21^{\text {st }}$ 2020 relative to the baseline mobility for that day of the week. The baseline is the median value for the corresponding day of the week in the five-week period between January $3^{\text {rd }}$ and February $6^{\text {th }} 2020$. The vertical line marks the start of the national lock-down on March $23^{\text {rd }} 2020$. Data: Google COVID-19 Community Mobility Reports. 
Figure A2: Average mobility in public spaces in German states
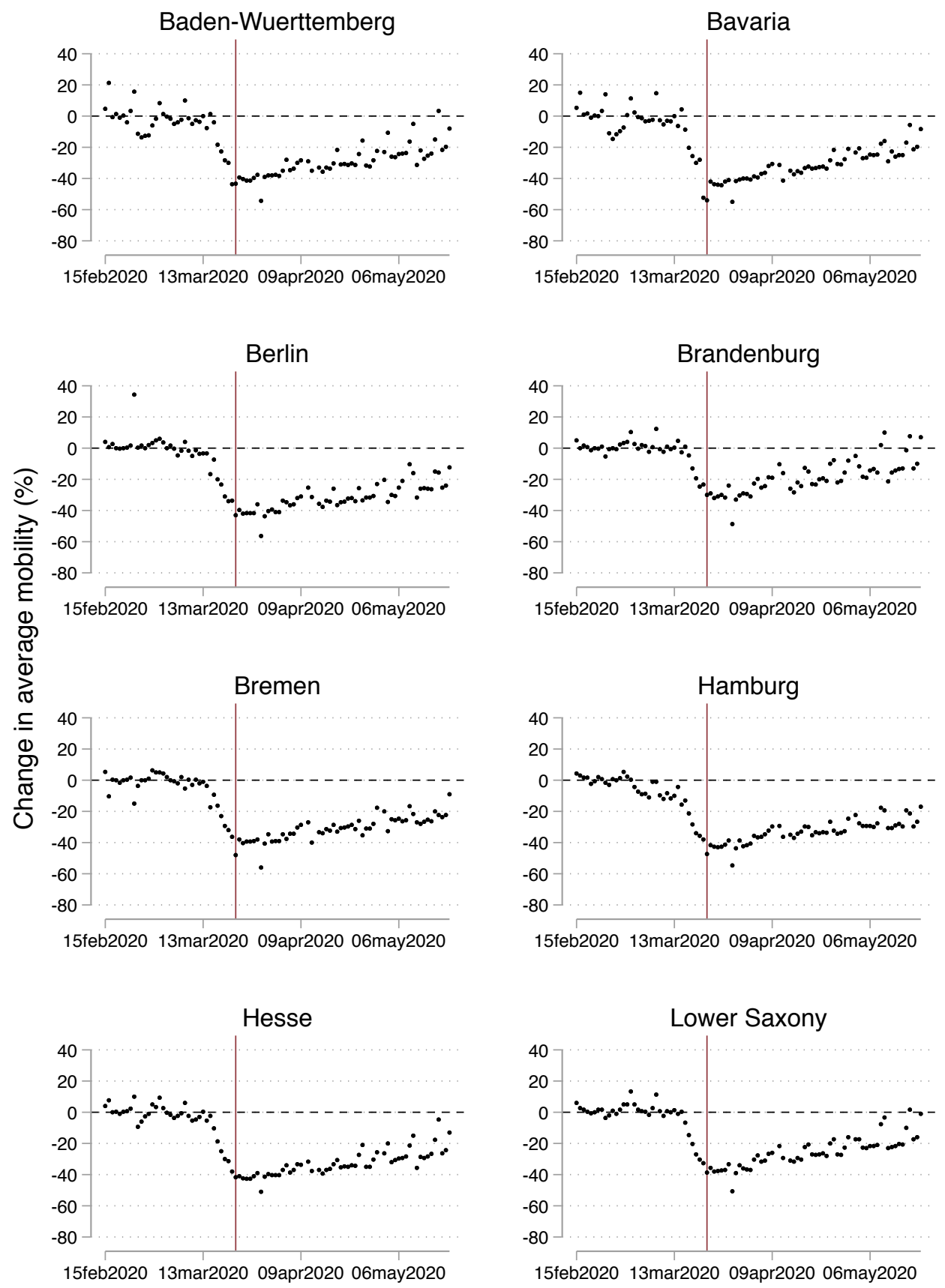

Note: Graphs shows the percentage change in average mobility in public spaces (groceries and pharmacies, workplaces, and transit stations) in each state for each day between February $15^{\text {th }}$ and May $21^{\text {st }} 2020$ relative to the baseline mobility for that day of the week. The baseline is the median value for the corresponding day of the week in the five-week period between January $3^{\text {rd }}$ and February $6^{\text {th }}$ 2020. The vertical line marks the start of the national lock-down on March $23^{\text {rd }} 2020$. Data: Google COVID-19 Community Mobility Reports. 
Figure A3: Average mobility in public spaces in German states (cont.)
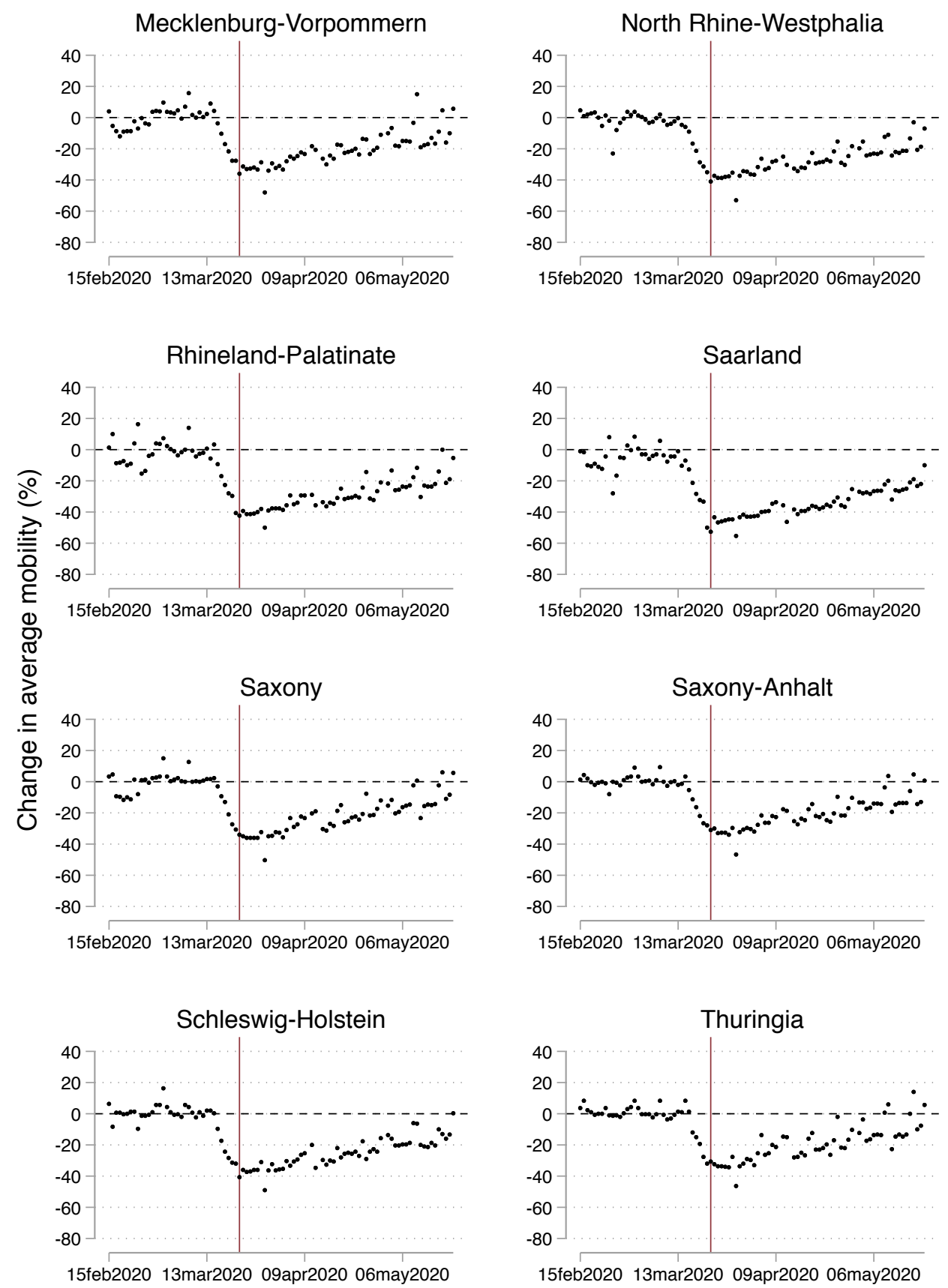

Note: Graphs shows the percentage change in average mobility in public spaces (groceries and pharmacies, workplaces, and transit stations) in each state for each day between February $15^{\text {th }}$ and May $21^{\text {st }} 2020$ relative to the baseline mobility for that day of the week. The baseline is the median value for the corresponding day of the week in the five-week period between January $3^{\text {rd }}$ and February $6^{\text {th }}$ 2020. The vertical line marks the start of the national lock-down on March $23^{\text {rd }} 2020$. Data: Google COVID-19 Community Mobility Reports. 


\section{Static DD estimates for other mobility measures}

This section presents estimates from the static DD model (Equation 1) for mobility in specific public locations.

Table A2: Effect of compulsory face mask policies on mobility in groceries and pharmacies

\begin{tabular}{lcccccc}
\hline & $(1)$ & $(2)$ & $(3)$ & $(4)$ & $(5)$ & $(6)$ \\
\hline & & & & & & \\
& & & & & \\
& & & & & \\
& $(1.091)$ & $(0.963)$ & $(0.971)$ & $(1.034)$ & $(1.051)$ & $(0.789)$ \\
State FE & & & & & & \\
Date FE & $\checkmark$ & $\checkmark$ & $\checkmark$ & $\checkmark$ & $\checkmark$ & $\checkmark$ \\
State-specific holidays & $\checkmark$ & $\checkmark$ & $\checkmark$ & $\checkmark$ & $\checkmark$ & $\checkmark$ \\
Lockdown relaxed & & $\checkmark$ & $\checkmark$ & $\checkmark$ & $\checkmark$ & $\checkmark$ \\
COVID-19 cases (t-1) & & $\checkmark$ & $\checkmark$ & $\checkmark$ & $\checkmark$ & $\checkmark$ \\
Sec. school open & & & $\checkmark$ & $\checkmark$ & $\checkmark$ & $\checkmark$ \\
Retail open & & & & $\checkmark$ & $\checkmark$ & $\checkmark$ \\
State ${ }^{*}$ Day-of-week FE & & & & & $\checkmark$ & $\checkmark$ \\
Observations & 957 & 957 & 957 & 957 & 957 & 957 \\
R-squared & 0.951 & 0.962 & 0.962 & 0.962 & 0.962 & 0.984 \\
Clusters & 16 & 16 & 16 & 16 & 16 & 16 \\
\hline Robust clustered standard errors in parentheses. ${ }^{* * *} \mathrm{p}<0.01, * * \mathrm{p}<0.05, * \mathrm{p}<0.1$ &
\end{tabular}

Table A3: Effect of compulsory face mask policies on mobility in workplaces

\begin{tabular}{lcccccc}
\hline & $(1)$ & $(2)$ & $(3)$ & $(4)$ & $(5)$ & $(6)$ \\
\hline & $2.129^{* * *}$ & $1.927^{* *}$ & $1.916^{* *}$ & 1.275 & 1.497 & 0.967 \\
Face mask policy & $(0.714)$ & $(0.810)$ & $(0.801)$ & $(0.986)$ & $(1.017)$ & $(0.833)$ \\
& & & & & & \\
State FE & $\checkmark$ & $\checkmark$ & $\checkmark$ & $\checkmark$ & $\checkmark$ & $\checkmark$ \\
Date FE & $\checkmark$ & $\checkmark$ & $\checkmark$ & $\checkmark$ & $\checkmark$ & $\checkmark$ \\
State-specific holidays & & $\checkmark$ & $\checkmark$ & $\checkmark$ & $\checkmark$ & $\checkmark$ \\
Lockdown relaxed & & $\checkmark$ & $\checkmark$ & $\checkmark$ & $\checkmark$ & $\checkmark$ \\
COVID-19 cases (t-1) & & & $\checkmark$ & $\checkmark$ & $\checkmark$ & $\checkmark$ \\
Sec. school open & & & & $\checkmark$ & $\checkmark$ & $\checkmark$ \\
Retail open & & & & & $\checkmark$ & $\checkmark$ \\
State * Day-of-week FE & & & & & & $\checkmark$ \\
Observations & 960 & 960 & 960 & 960 & 960 & 960 \\
R-squared & 0.974 & 0.978 & 0.979 & 0.979 & 0.979 & 0.989 \\
Clusters & 16 & 16 & 16 & 16 & 16 & 16 \\
\hline Robust clustered standard errors in parentheses. ${ }^{* * *} \mathrm{p}<0.01, * *$ & $\mathrm{p}<0.05,{ }^{*} \mathrm{p}<0.1$
\end{tabular}


Table A4: Effect of compulsory face mask policies on mobility in transit stations

\begin{tabular}{lcccccc}
\hline & $(1)$ & $(2)$ & $(3)$ & $(4)$ & $(5)$ & $(6)$ \\
\hline & & & & & & \\
Face mask policy & -0.094 & -0.620 & -0.630 & -1.642 & -1.614 & $-1.593^{*}$ \\
& $(1.117)$ & $(0.978)$ & $(0.988)$ & $(1.259)$ & $(1.195)$ & $(0.907)$ \\
State FE & & & & & & \\
Date FE & $\checkmark$ & $\checkmark$ & $\checkmark$ & $\checkmark$ & $\checkmark$ & $\checkmark$ \\
State-specific holidays & & $\checkmark$ & $\checkmark$ & $\checkmark$ & $\checkmark$ & $\checkmark$ \\
Lockdown relaxed & & $\checkmark$ & $\checkmark$ & $\checkmark$ & $\checkmark$ & $\checkmark$ \\
COVID-19 cases (t-1) & & & $\checkmark$ & $\checkmark$ & $\checkmark$ & $\checkmark$ \\
Sec. school open & & & $\checkmark$ & $\checkmark$ & $\checkmark$ & $\checkmark$ \\
Retail open & & & & $\checkmark$ & $\checkmark$ & $\checkmark$ \\
State * Day-of-week FE & & & & & $\checkmark$ & $\checkmark$ \\
Observations & 960 & 960 & 960 & 960 & 960 & $\checkmark 60$ \\
R-squared & 0.917 & 0.920 & 0.920 & 0.921 & 0.921 & 0.948 \\
Clusters & 16 & 16 & 16 & 16 & 16 & 16 \\
\hline Robust clustered standard errors in parentheses. ${ }^{* * *} \mathrm{p}<0.01,{ }^{* *} \mathrm{p}<0.05, * \mathrm{p}<0.1$
\end{tabular}

Table A5: Effect of compulsory face mask policies on time spent at home

(1)

$(2)$

(3)

(4)

$(5)$

(6)

Face mask policy

$\begin{array}{cc}0.083 & 0.257^{*} \\ (0.220) & (0.094) \\ & \\ \checkmark & \checkmark \\ \checkmark & \checkmark \\ & \checkmark \\ & \checkmark\end{array}$

State FE

Date FE

State-specific holidays

Lockdown relaxed

COVID-19 cases (t-1)

Sec. school open

Retail open

State * Day-of-week FE

Observations

R-squared

$960 \quad 960$

$0.255^{* *}$

$0.445^{* * *}$

$0.450^{* * *}$

0.222

$(0.095) \quad(0.134)$

$(0.138)$

$(0.171)$

Clusters

$0.973 \quad 0.975$
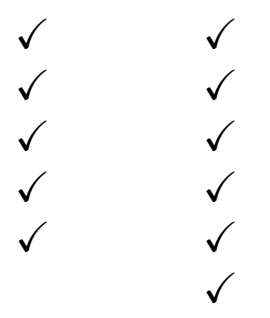

Robust clustered standard errors in parentheses

\begin{tabular}{cccc}
960 & 960 & 960 & 960 \\
0.975 & 0.975 & 0.975 & 0.985 \\
16 & 16 & 16 & 16 \\
\hline eses. ${ }^{* * *} \mathrm{p}<0.01,{ }^{* *} \mathrm{p}<0.05,{ }^{*} \mathrm{p}<0.1$
\end{tabular}




\section{Parallel trends}

This section examines parallel trends using the fully dynamic event study specification (Equation 2).

Figure A4: Fully dynamic event study estimates for average mobility in public spaces

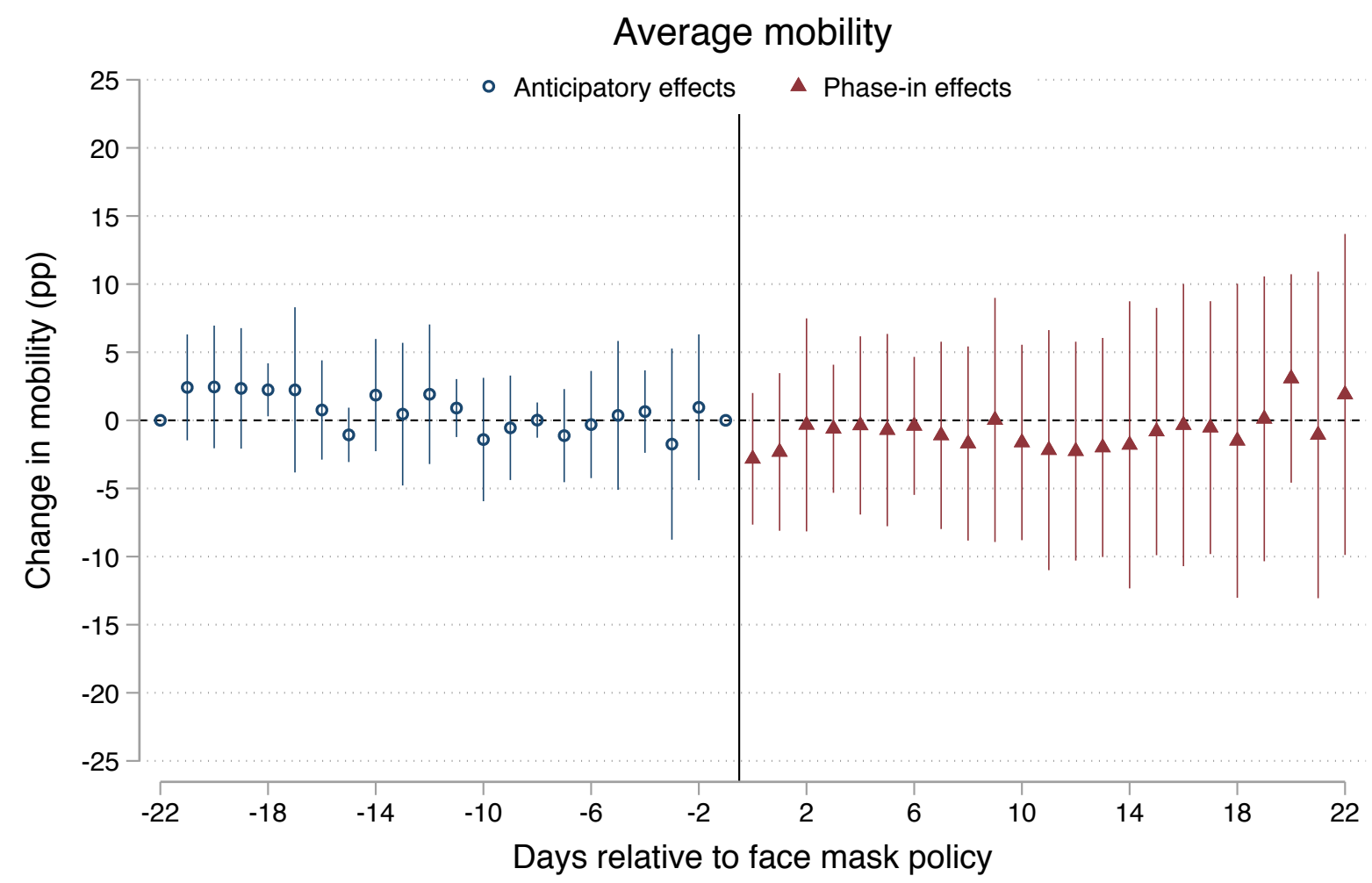

Note: This graph shows the estimated anticipatory and over-time effects of compulsory face mask policies on average mobility in public spaces (groceries and pharmacies, workplaces, and transit stations) for 22 days before and after the policy change. Point estimates are obtained from a fully dynamic event study model, where the first and last treatment leads are set to zero and the panel is "trimmed" such that it is balanced in time periods (days) relative to the policy change. Vertical lines represent cluster-robust 95\% confidence intervals. The model includes controls from our preferred static DD model specification: state-specific public holidays, the daily number of new COVID-19 cases in each state (lagged by one day), and dummies for policy changes that likely affect community mobility (lock-down rules being relaxed, secondary schools and retail re-opening). 
Figure A5: Fully dynamic event study estimates for other mobility measures
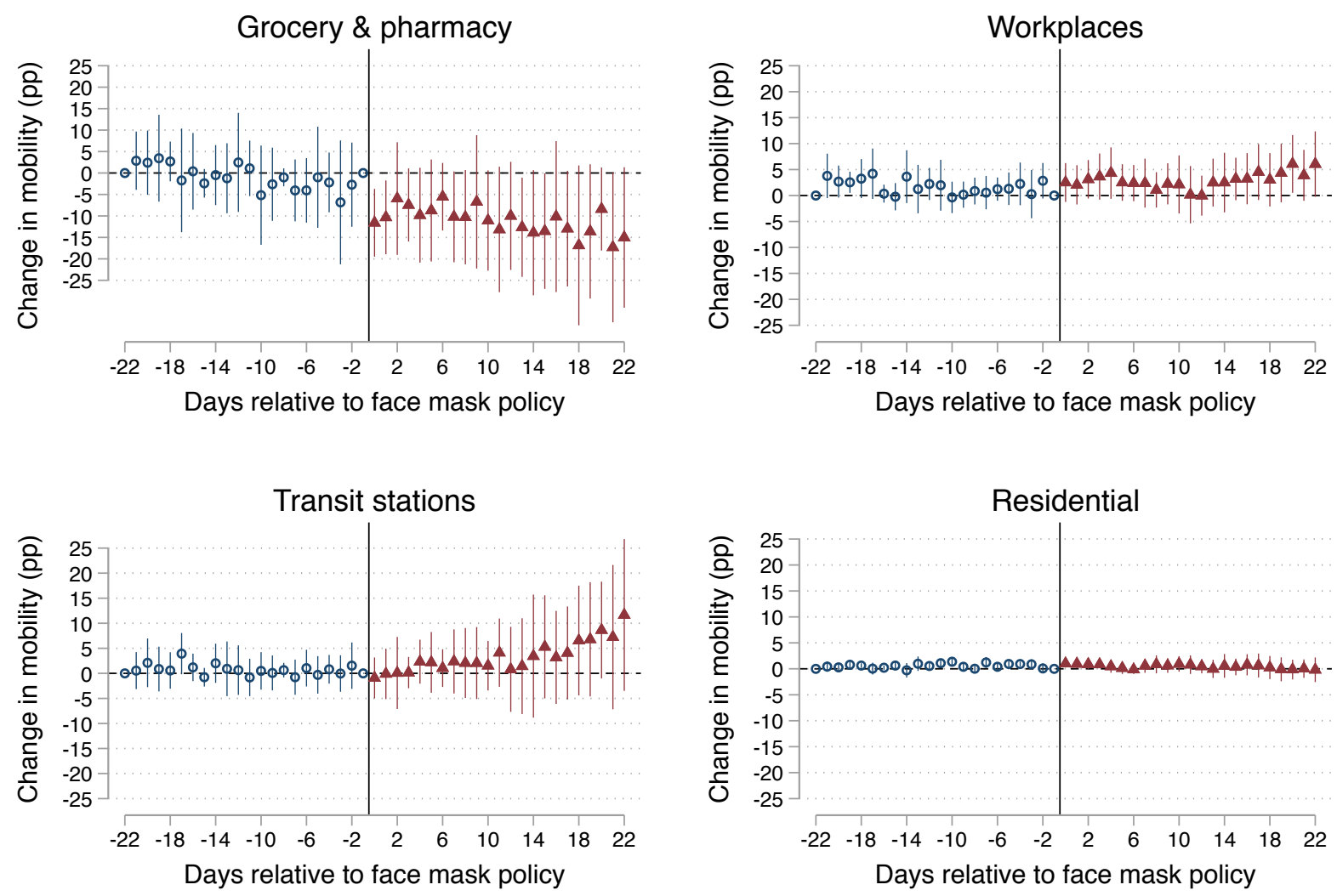

- Anticipatory effects

- Phase-in effects

Note: This graph shows the estimated anticipatory and over-time effects of compulsory face mask policies on mobility (shown separately for groceries and pharmacies, workplaces, transit stations, and places of residence) for 22 days before and after the policy change. Point estimates are obtained from a fully dynamic event study model, where the first and last treatment leads are set to zero and the panel is "trimmed" such that it is balanced in time periods (days) relative to the policy change. Vertical lines represent cluster-robust 95\% confidence intervals. Models include controls from our preferred static DD model specification: state-specific public holidays, the daily number of new COVID-19 cases in each state (lagged by one day), and dummies for policy changes that likely affect community mobility (lock-down rules being relaxed, secondary schools and retail re-opening). 


\title{
E Semi-dynamic estimates for other mobility measures
}

Figure A6 shows semi-dynamic event study (see Equation 3) estimates for measures of mobility in specific public spaces as well as hours spent in places of residence.

Figure A6: Semi-dynamic event study estimates for other mobility measures
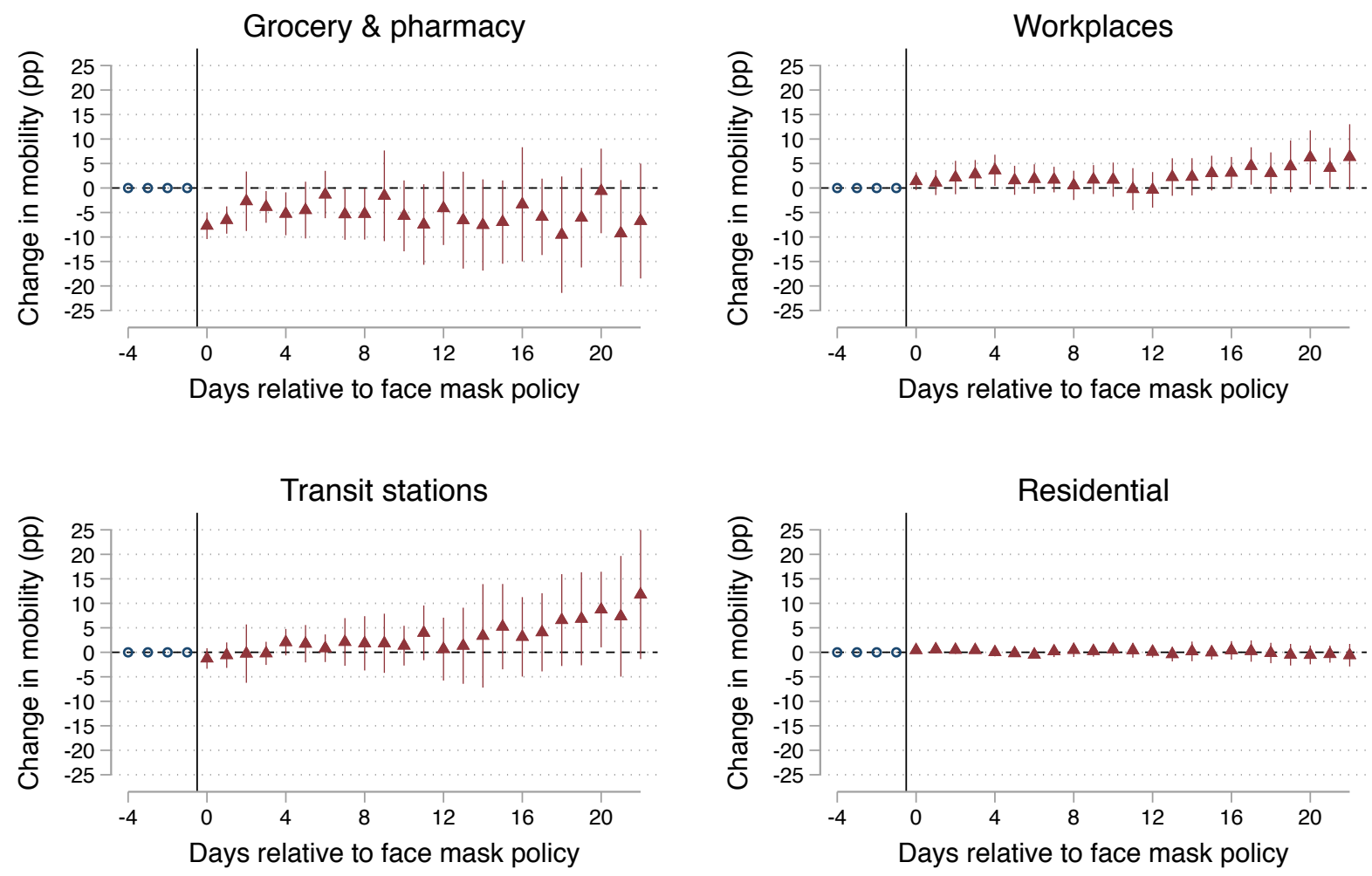

\section{- Anticipatory effects $\Delta$ Phase-in effects \\ (set to zero)}

\begin{abstract}
Note: This graph shows the estimated over-time effects of compulsory face mask policies on mobility (shown separately for groceries and pharmacies, workplaces, transit stations, and places of residence) for 22 days after the policy change. Point estimates are obtained from a semi-dynamic event study model, where all treatment leads are set to zero and the panel is "trimmed" such that it is balanced in time periods (days) relative to the policy change. Vertical lines represent cluster-robust 95\% confidence intervals. Models include controls from our preferred static DD model specification: state-specific public holidays, the daily number of new COVID-19 cases in each state (lagged by one day), and dummies for policy changes that likely affect community mobility (lock-down rules being relaxed, secondary schools and retail re-opening).
\end{abstract}




\section{F Robustness checks}

\section{F.1 Fully dynamic binned specification}

The fully dynamic binned model is specified as follows:

$$
Y_{s t}=\alpha_{s}+\beta_{t}+\mu_{\underline{g}} \sum_{\ell<-21} D_{s t}^{\ell}+\sum_{\ell=-21}^{-2} \gamma_{\ell} D_{s t}^{\ell}+\sum_{\ell=0}^{21} \gamma_{\ell} D_{s t}^{\ell}+\mu_{\bar{g}} \sum_{\ell>21} D_{s t}^{\ell}+X_{s t}^{\prime}+\epsilon_{s t}
$$

where distant relative periods $(|\ell|>21)$ are binned into $g=[-T,-21)$ and $\bar{g}=(21, T]$ and $T$ denotes all available calendar time periods (i.e. dates) in the data. In the binned specification, the panel is balanced in calendar time periods rather than in periods relative to the treatment. Only one lead (where $\ell=-1$ ) is set to zero.

Figures A7 and A8 show, respectively, estimates from fully dynamic "binned" event study models for measures of average mobility and mobility in specific locations. 
Figure A7: Fully-dynamic binned event study estimates for average mobility

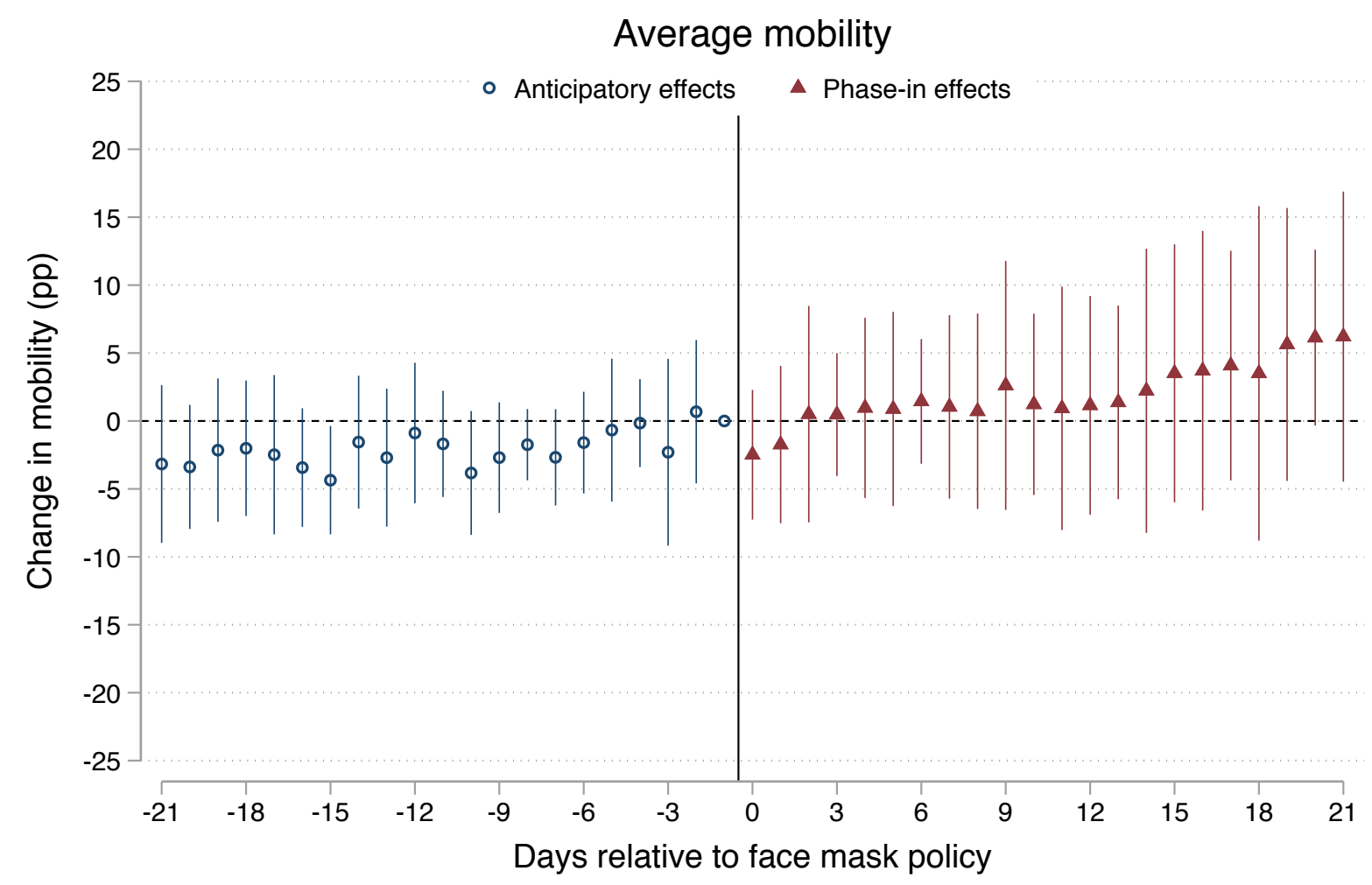

Note: This graph shows the estimated anticipatory and over-time effects of compulsory face mask policies on average mobility (groceries and pharmacies, workplaces, transit stations) for 22 days before and after the policy change. Point estimates are obtained from a fully-dynamic event study model, where the first treatment lead is set to zero. The most distant leads and lags are "binned" and not displayed. The panel is balanced in calendar time periods. Vertical lines represent cluster-robust $95 \%$ confidence intervals. The model includes controls from our preferred static DD model specification: state-specific public holidays, the daily number of new COVID-19 cases in each state (lagged by one day), and dummies for policy changes that likely affect community mobility (lock-down rules being relaxed, secondary schools and retail re-opening). 
Figure A8: Fully-dynamic binned event study estimates for other measures of mobility
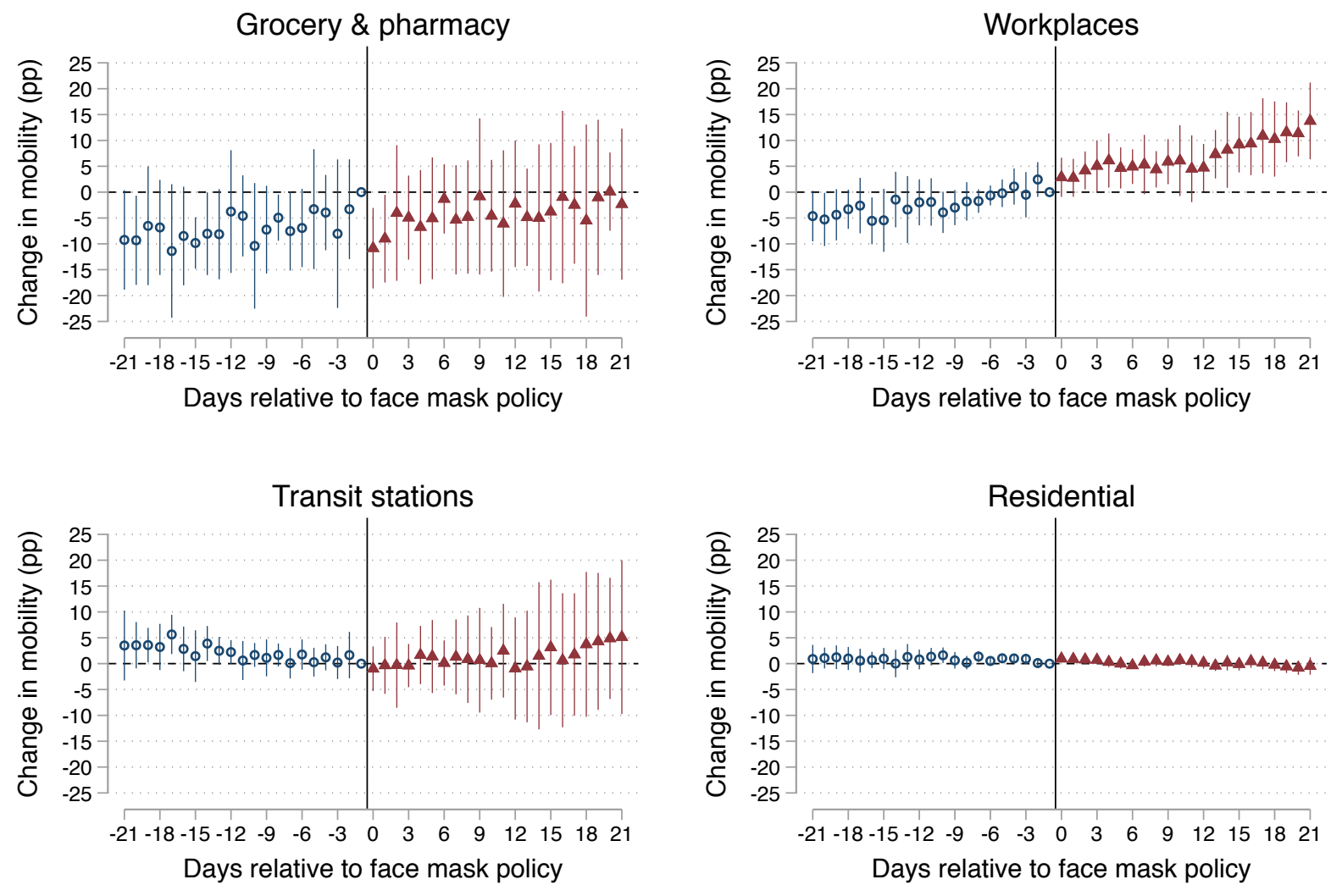

- Anticipatory effects

A Phase-in effects

Note: This graph shows the estimated anticipatory and over-time effects of compulsory face mask policies on mobility (shown separately for groceries and pharmacies, workplaces, transit stations, and places of residence) for 22 days before and after the policy change. Point estimates are obtained from a fullydynamic event study model, where the first treatment lead is set to zero. The most distant leads and lags are "binned" and not displayed. The panel is balanced in calendar time periods. Vertical lines represent cluster-robust 95\% confidence intervals. Models include controls from our preferred static DD model specification: state-specific public holidays, the daily number of new COVID-19 cases in each state (lagged by one day), and dummies for policy changes that likely affect community mobility (lock-down rules being relaxed, secondary schools and retail re-opening). 


\section{F.2 Never-treated control group}

We re-run the main static DD specification (Equation 1) using a control group of states that are never exposed to the treatment. Given that all states in Germany eventually implemented compulsory face mask policies, we create an "artificial" control group. To this end, we drop all observations from April $27^{\text {th }}$ onward. The three states that made face masks compulsory before April $27^{\text {th }}$ now constitute the treatment group and the remaining thirteen states are part of the artificial never-treated control group. The results are presented in Table A6 below.

Table A6: Effect of compulsory face mask policies on average mobility in public spaces (with never-treated control group)

\begin{tabular}{lcccccc}
\hline & $(1)$ & $(2)$ & $(3)$ & $(4)$ & $(5)$ & $(6)$ \\
\hline & & & & & & \\
Face mask policy & 0.860 & 0.080 & 0.147 & 0.136 & 0.111 & -1.090 \\
& $(1.013)$ & $(1.463)$ & $(1.495)$ & $(1.714)$ & $(1.697)$ & $(1.455)$ \\
State FE & & & & & & \\
Date FE & $\checkmark$ & $\checkmark$ & $\checkmark$ & $\checkmark$ & $\checkmark$ & $\checkmark$ \\
State-specific holidays & $\checkmark$ & $\checkmark$ & $\checkmark$ & $\checkmark$ & $\checkmark$ & $\checkmark$ \\
Lockdown relaxed & & $\checkmark$ & $\checkmark$ & $\checkmark$ & $\checkmark$ & $\checkmark$ \\
COVID-19 cases (t-1) & & $\checkmark$ & $\checkmark$ & $\checkmark$ & $\checkmark$ & $\checkmark$ \\
Sec. school open & & & $\checkmark$ & $\checkmark$ & $\checkmark$ & $\checkmark$ \\
Retail open & & & & $\checkmark$ & $\checkmark$ & $\checkmark$ \\
State $*$ Day-of-week FE & & & & & $\checkmark$ & $\checkmark$ \\
Observations & 560 & 560 & 560 & 560 & 560 & 560 \\
R-squared & 0.971 & 0.971 & 0.971 & 0.971 & 0.971 & 0.986 \\
Clusters & 16 & 16 & 16 & 16 & 16 & 16 \\
\hline Robust clustered standard errors in parentheses. ${ }^{* * *} \mathrm{p}<0.01, * * \mathrm{p}<0.05, * \mathrm{p}<0.1$
\end{tabular}


As an additional robustness check, we also run a fully dynamic "binned" event study specification (Equation 5) using the never-treated control group sample, where all observations from April $27^{\text {th }}$ onward are dropped. We do not employ the "trimming" approach because it is not possible to obtain a panel that is balanced in periods relative to the treatment (as 13 states do not have any post-treatment periods in this sample).

The $6^{\text {th }}$ lag of the treatment indicator is the last possible lag in the data, given that we have dropped all observations from April $27^{\text {th }}$ onward and Sachsen was the first state to implement a compulsory face mask policy six days before (on April $20^{\text {th }}$ ). The $6^{\text {th }}$ lag is effectively a "switch-on-stay-on" indicator as the panel ends on April 26 ${ }^{\text {th }}$. Equivalently, we treat the $6^{\text {th }}$ lead of the treatment indicator as the first lead in the data and code it as a "switch-on-stay-on" indicator. As a result, we have a panel that is balanced in calendar periods.

The fully dynamic binned model (with never-treated control group) is specified as follows:

$$
Y_{s t}=\alpha_{s}+\beta_{t}+\mu_{\underline{g}} \sum_{\ell<-5} D_{s t}^{\ell}+\sum_{\ell=-5}^{-2} \gamma_{\ell} D_{s t}^{\ell}+\sum_{\ell=0}^{5} \gamma_{\ell} D_{s t}^{\ell}+\mu_{\bar{g}} \sum_{\ell>5} D_{s t}^{\ell}+X_{s t}^{\prime}+\epsilon_{s t}
$$

where distant relative periods $(|\ell|>5)$ are binned into $\underline{g}=[-T,-5)$ and $\bar{g}=(5, T]$ and $T$ denotes all available calendar time periods (i.e. dates) in the data. In the binned specification, the panel is balanced in calendar time periods rather than in periods relative to the treatment. Only one lead (where $\ell=-1$ ) is set to zero.

Figure A9 presents the results from this model specification. As in the static DD analysis, the outcome is average mobility in public spaces in Germany. 
Figure A9: Fully-dynamic binned event study estimates for average mobility (with never-treated control group)

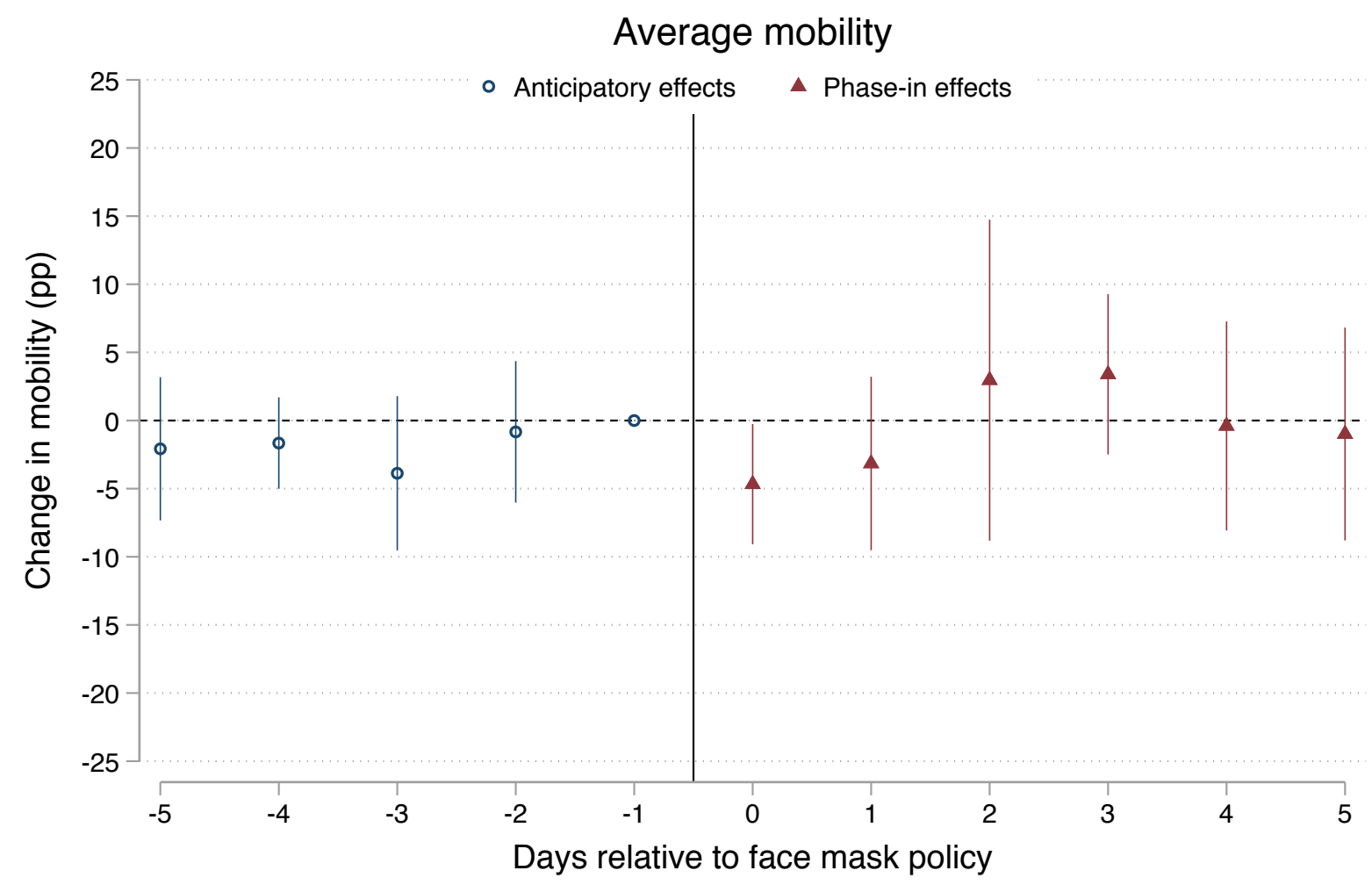

Note: This graph shows the estimated anticipatory and over-time effects of compulsory face mask policies on average mobility (groceries and pharmacies, workplaces, transit stations) for 6 days before and after the policy change. Point estimates are obtained from a fully-dynamic event study model, where the first treatment lead is set to zero. The most distant leads and lags are "binned" and not displayed. The panel is balanced in calendar time periods. Vertical lines represent cluster-robust $95 \%$ confidence intervals. The model includes controls from our preferred static DD model specification: state-specific public holidays, the daily number of new COVID-19 cases in each state (lagged by one day), and dummies for policy changes that likely affect community mobility (lock-down rules being relaxed, secondary schools and retail re-opening).

\section{F.3 Wild cluster bootstrap}

We employ a wild cluster bootstrap procedure to obtain more accurate p-values. Intuitively, the procedure generates many bootstrap samples that mimic the distribution from which the original sample was obtained. It then computes a t-statistic for the coefficient of interest in each bootstrap sample. The refined p-value is the proportion of the bootstrap t-statistics that are more extreme than the t-statistic obtained from the original sample [Angrist and Pischke, 2009]. 
In a setting with very few treated clusters, the standard wild cluster bootstrap will typically under-reject the null of no treatment effect when the null is imposed (restricted). The restricted specification is the one from which we obtain the refined p-values reported in the main results table (Table 2). In contrast, the standard wild cluster bootstrap will over-reject when the null is not imposed (unrestricted) [MacKinnon and Webb, 2018, Roodman et al., 2019]. To account for this problem, we also employ the "sub-cluster" wild bootstrap procedure proposed by MacKinnon and Webb [2018], where the wild bootstrap data-generating process is clustered at a finer level (i.e. state-date level) than the covariance matrix (i.e. state level).

In Table A7 we report results from static DD models predicting our main outcome (average mobility), with refined p-values from a wild cluster bootstrap procedure, where the datagenerating process is clustered at the state-date level (and the null is imposed).

Table A7: Effect of compulsory face mask policies on mobility in public spaces

\begin{tabular}{|c|c|c|c|c|c|c|}
\hline & (1) & $(2)$ & $(3)$ & $(4)$ & $(5)$ & $(6)$ \\
\hline Face mask policy & $\begin{array}{c}-0.759 \\
(0.703) \\
{[0.366]}\end{array}$ & $\begin{array}{l}-1.075 \\
(0.692) \\
{[0.211]}\end{array}$ & $\begin{array}{l}-1.074 \\
(0.700) \\
{[0.214]}\end{array}$ & $\begin{array}{l}-1.591 \\
(0.946) \\
{[0.211]}\end{array}$ & $\begin{array}{c}-1.500 \\
(0.924) \\
{[0.228]}\end{array}$ & $\begin{array}{c}-1.763^{* *} \\
(0.605) \\
{[0.040]}\end{array}$ \\
\hline State FE & $\checkmark$ & $\checkmark$ & $\checkmark$ & $\checkmark$ & $\checkmark$ & $\checkmark$ \\
\hline Date FE & $\checkmark$ & $\checkmark$ & $\checkmark$ & $\checkmark$ & $\checkmark$ & $\checkmark$ \\
\hline State-specific holidays & & $\checkmark$ & $\checkmark$ & $\checkmark$ & $\checkmark$ & $\checkmark$ \\
\hline Lockdown relaxed & & $\checkmark$ & $\checkmark$ & $\checkmark$ & $\checkmark$ & $\checkmark$ \\
\hline COVID-19 cases (t-1) & & & $\checkmark$ & $\checkmark$ & $\checkmark$ & $\checkmark$ \\
\hline Sec. school open & & & & $\checkmark$ & $\checkmark$ & $\checkmark$ \\
\hline Retail open & & & & & $\checkmark$ & $\checkmark$ \\
\hline State ${ }^{*}$ Day-of-week FE & & & & & & $\checkmark$ \\
\hline Observations & 960 & 960 & 960 & 960 & 960 & 960 \\
\hline R-squared & 0.965 & 0.973 & 0.973 & 0.973 & 0.973 & 0.985 \\
\hline Clusters & 16 & 16 & 16 & 16 & 16 & 16 \\
\hline
\end{tabular}

\section{F.4 State-week clustered standard errors}

We re-run the main static DD specification (Equation 1) using robust standard errors clustered at the state-week level (rather than the state-level). 
Table A8: Effect of compulsory face mask policies on mobility in public spaces (with robust standard errors clustered at the state-week level)

\begin{tabular}{lcccccc}
\hline & $(1)$ & $(2)$ & $(3)$ & $(4)$ & $(5)$ & $(6)$ \\
\hline & & & & & & \\
Face mask policy & -0.759 & -1.075 & -1.070 & -1.588 & -1.494 & $-1.763^{* *}$ \\
& $(1.218)$ & $(1.228)$ & $(1.230)$ & $(1.480)$ & $(1.513)$ & $(0.844)$ \\
& & & & & & \\
State FE & $\checkmark$ & $\checkmark$ & $\checkmark$ & $\checkmark$ & $\checkmark$ & $\checkmark$ \\
Date FE & $\checkmark$ & $\checkmark$ & $\checkmark$ & $\checkmark$ & $\checkmark$ & $\checkmark$ \\
State-specific holidays & & $\checkmark$ & $\checkmark$ & $\checkmark$ & $\checkmark$ & $\checkmark$ \\
Lockdown relaxed & & $\checkmark$ & $\checkmark$ & $\checkmark$ & $\checkmark$ & $\checkmark$ \\
COVID-19 cases (t-1) & & & $\checkmark$ & $\checkmark$ & $\checkmark$ & $\checkmark$ \\
Sec. school open & & & & $\checkmark$ & $\checkmark$ & $\checkmark$ \\
Retail open & & & & & $\checkmark$ & $\checkmark$ \\
State * Day-of-week FE & & & & & & $\checkmark$ \\
Observations & 960 & 960 & 960 & 960 & 960 & 960 \\
R-squared & 0.968 & 0.976 & 0.976 & 0.976 & 0.976 & 0.987 \\
Clusters & 144 & 144 & 144 & 144 & 144 & 144 \\
\hline Robust standard
\end{tabular}

Robust standard errors clustered at the state-week level in parentheses. $* * * \mathrm{p}<0.01,{ }^{* *} \mathrm{p}<0.05,{ }^{*} \mathrm{p}<0.1$ 


\section{F.5 Synthetic control method}

The synthetic control (SC) method is an alternative approach for evaluating aggregatelevel policy interventions that relaxes the parallel trends assumption of the DD design. Specifically, the synthetic control design allows the effects of unobserved variables on the outcome to vary with time [Abadie et al., 2010]. Intuitively, the synthetic control design weighs outcomes from available control units (often referred to as the "donor pool") so as to construct the counterfactual outcome for the treated unit in the absence of the treatment. A synthetic control unit is defined as the time-invariant weighted average of available control units, which have similar pre-intervention characteristics and outcome trajectories as the treated unit [Kreif et al., 2016].

Weights are chosen so that the resulting synthetic control unit best reproduces the values of a set of predictors of the outcome (community mobility) in the treated unit before the implementation of the compulsory face mask policy. Specifically, weights are chosen so that the mean squared prediction error of the outcome variable in the pre-treatment period (also called pre-treatment root mean squared predictive error or "RMSPE") is minimised [Abadie et al., 2010]. We use the following pre-treatment predictors: population density per $\mathrm{km}^{2}$, GDP per inhabitant, population aged 25-64 with upper and post secondary education, employment in the service sector as \% of total employment, and long-term unemployment as $\%$ of the active population. All data are for the year 2014 (we assume that the predictors are relatively stable over time) and come from the latest Quality of Government EU Regional database. ${ }^{9}$ In addition, the synthetic control model is augmented by adding average mobility outcomes for three dates prior to the policy change (March $23^{\text {rd }}$, April $5^{\text {th }}$, and the last day prior to the policy change) as predictors. Using these predictors results in a synthetic control that has common pre-treatment trends with the treated state.

To obtain a panel with never-treated control units, which is balanced in calendar periods (days) and units (states), we drop all observations from April $27^{\text {th }}$ onward. Only three states made face masks compulsory before April $27^{\text {th }}$ : Saxony (April $20^{\text {th }}$ ), Saxony-Anhalt (April $23^{\text {rd }}$ ), and Thuringia (April 24 $4^{\text {th }}$ ). Here, we focus on comparing Saxony to its synthetic control, given that this state was the first to implement the face mask policy and therefore has the longest available post-treatment period (seven days). The two other early-movers (Saxony-Anhalt and Thuringia) are excluded so that all states in the "donor pool" are never-treated controls. The remaining 13 states represent our "donor pool" from which we construct the synthetic control unit for Saxony. Table A9 shows the means of all pretreatment predictors used in the synthetic control analysis for the real Saxony, the synthetic Saxony, and all 13 states in the "donor pool". It shows that the synthetic Saxony more closely resembles the real Saxony on all pre-treatment characteristics compared to the rest of Germany.

The results from the synthetic control analysis for Saxony are shown in Figure A10. Overall, the results suggest that the compulsory face mask policy did not affect community mobility

\footnotetext{
${ }^{9}$ Available at: https://qog.pol.gu.se/data/datadownloads/qogeuregionaldata
} 
patterns in Saxony. This is because the post-treatment mobility trends in Saxony closely track the mobility trends in its synthetic counterpart.

To assess the significance of our synthetic control estimates, we also conduct a series of placebo tests. Specifically, we apply the synthetic control procedure to every potential control state in the sample (i.e. the 13 states in the "donor pool"). This allows us to assess whether the effect estimated by the synthetic control for the treated state is large relative to the effect estimated for a state chosen at random [Abadie et al., 2010, Galiani and Quistorff, 2017]. Figure A11 shows results from the placebo tests. The results suggest that there are no statistically significant differences in post-treatment mobility patterns between the real and the synthetic Saxony.

Table A9: Means of pre-treatment characteristics

\begin{tabular}{lccc}
\hline & Saxony (mean) & Synthetic Saxony (mean) & Rest of Germany (mean) \\
\hline Pop. density per km² & 219.9 & 165.4 & 738.8 \\
GDP per inhabitant & 26900 & 31379 & 35979 \\
Pop. aged 25-64 with sec. edu. & 67.40 & 62.70 & 59.84 \\
\% employed in service sector & 68.60 & 69.58 & 73.44 \\
\% long-term unemploymed & 3.800 & 2.797 & 2.571 \\
\hline
\end{tabular}

Note: All data are for the year 2014 and from the Quality of Government EU Regional database. The synthetic control model is augmented by adding average mobility outcomes for three dates prior to the policy change (means not reported here). The dates are March $23^{\text {rd }}$, April $5^{\text {th }}$, and April $19^{\text {th }}$. Rest of Germany refers to the 13 states in the "donor pool", which excludes Saxony-Anhalt and Thuringia. 
Figure A10: Average mobility in Saxony vs. synthetic Saxony

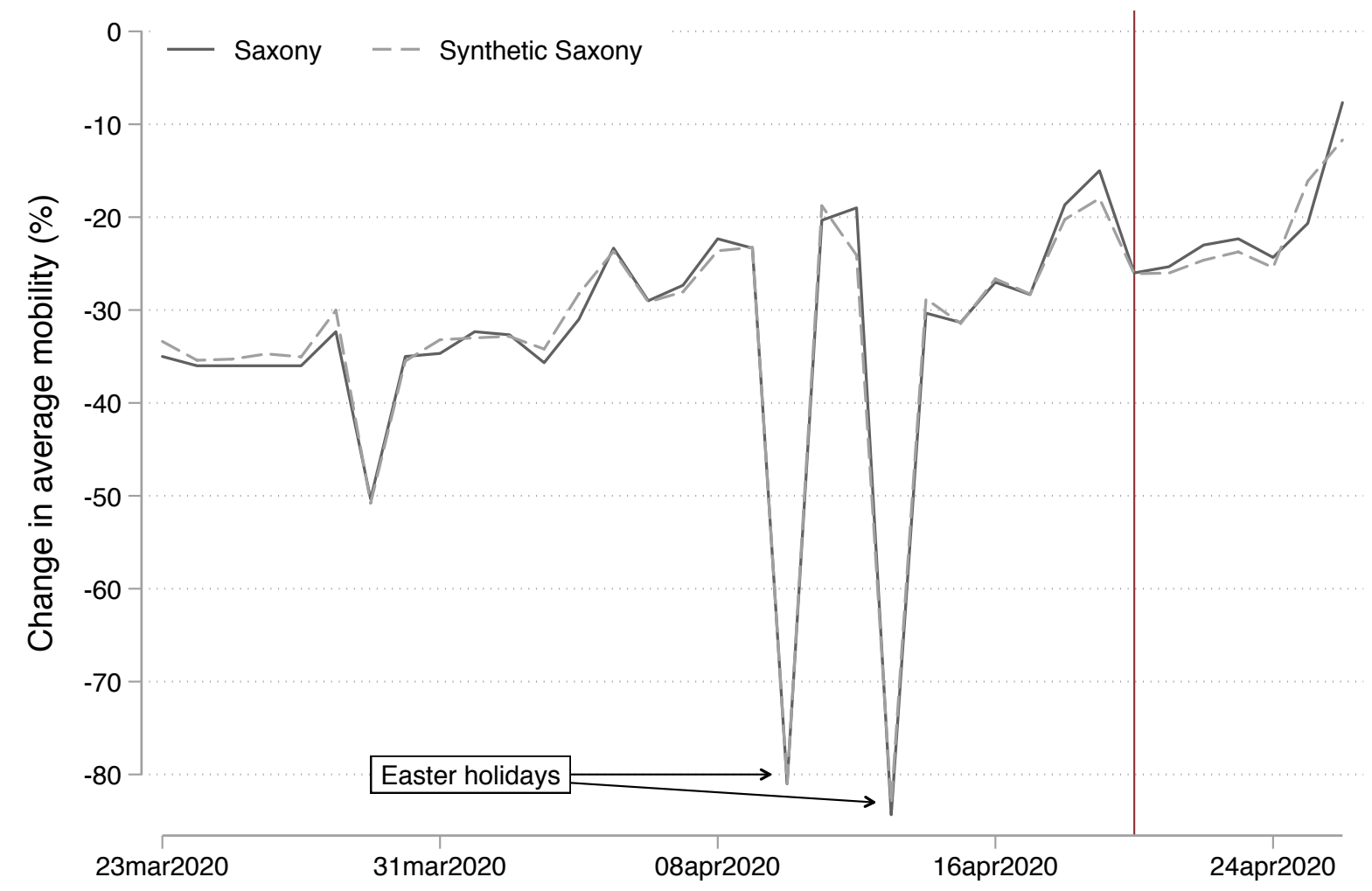

Note: This graph shows the percentage change in average mobility in public spaces (groceries and pharmacies, workplaces, and transit stations) in Saxony (solid line) vs. synthetic Saxony (dashed line) for each day between Mar $23^{\text {rd }}$ and Apr $27^{\text {th }} 2020$ relative to the baseline. The baseline is the median value for the corresponding day of the week in the five-week period between Jan $3^{\text {rd }}$ and Feb $6^{\text {th }} 2020$. The vertical line marks Apr $20^{\text {th }}$ - when the compulsory face mask policy was implemented in Saxony. Predictors for the synthetic control are population density per $\mathrm{km}^{2}$, GDP per inhabitant, population aged 25-64 with upper and post secondary education, employment in services as $\%$ of total employment, long-term unemployment as $\%$ of the active population, change in average mobility on Mar $23^{\text {rd }}$, Apr $5^{\text {th }}$ and Apr $19^{\text {th }}$. Weights: Baden-Wuerttemberg $=0.392$, Brandenburg $=0.468$, Mecklenburg-Vorpommern $=0.140$, all other states $=0$. 
Figure A11: Placebo tests for Saxony

(a) Outcome trends
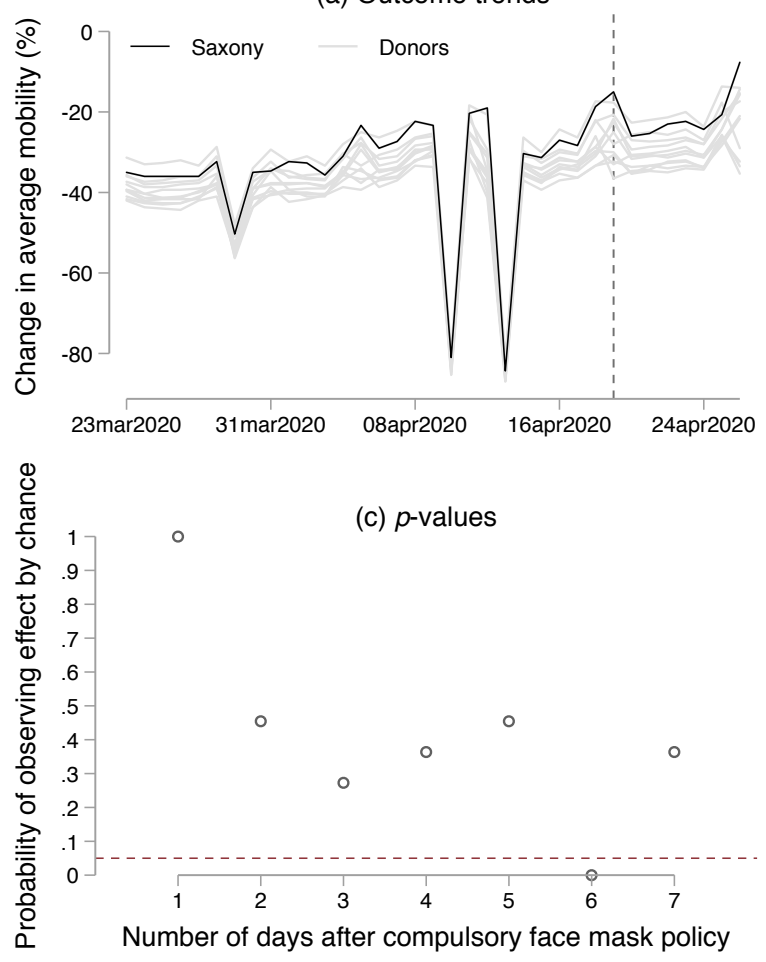

(b) Effects

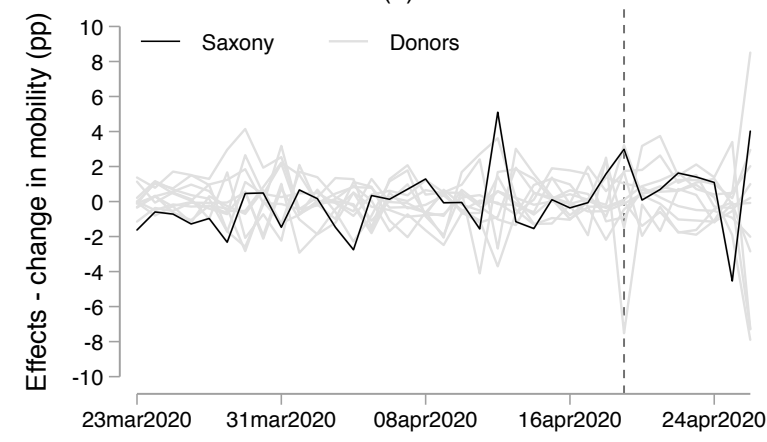

(d) $p$-values (pseudo t-stats)

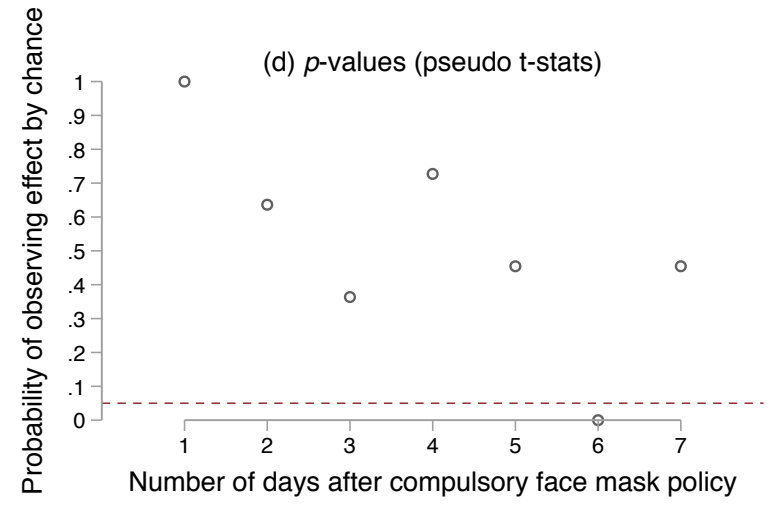

Note: (a) This graph shows the percentage change in average mobility in public spaces (groceries and pharmacies, workplaces, and transit stations) in Saxony (black line) and placebo states (grey lines) for each day between Mar $23^{\text {rd }}$ and Apr $27^{\text {th }} 2020$ relative to the baseline. The baseline is the median value for the corresponding day of the week in the five-week period between Jan $3^{\text {rd }}$ and Feb $6^{\text {th }} 2020$. (b) This graph shows the estimated effects (in pp) of the compulsory face mask policy on average mobility for Saxony (black line) and placebo states (grey lines). The dashed vertical lines mark the last pre-treatment period. (c) This graph shows the proportions of placebo effects that are at least as large as the main effect for each post-treatment period. (d) This graph shows the proportions of placebo pseudo t-statistics (unit's effect divided by its pre-treatment RMSPE) that are at least as large as the main pseudo t-statistic for each post-treatment period. The dashed horizontal lines mark the critical value of 0.05. Predictors for the synthetic control are population density per $\mathrm{km}^{2}$, GDP per inhabitant, population aged 25-64 with upper and post secondary education, employment in services as \% of total employment, long-term unemployment as $\%$ of the active population, change in average mobility on Mar $23^{\text {rd }}$, Apr $5^{\text {th }}$ and Apr $19^{\text {th }}$. 